\title{
Regional Wave Propagation from Mexican Subduction Zone Earthquakes: The Attenuation Functions for Interplate and Inslab Events
}

\author{
by T. Furumura and S. K. Singh
}

\begin{abstract}
The seismic waves from subduction zone earthquakes are significantly affected by the presence of 3D variation in crust and upper-mantle structure around the source area. These heterogeneous structures also profoundly modify the character of seismic waves as they propagate from the source area to regional distances. This is illustrated by studying shallow, interplate earthquakes along the Mexican subduction zone, and deeper, inslab, normal-faulting earthquakes in the subducted Cocos plate beneath Mexican mainland. The strong-motion recordings of these earthquakes are used to evaluate the character of wave propagation along the path between the source region and Mexico City. We compare the wavefield from two large earthquakes of different source type. During the shallow $(H=17 \mathrm{~km})$, interplate, 1995 Guerrero earthquake $\left(M_{\mathrm{w}} 7.3\right)$, the $L g$ phase is the most prominent feature at regional distances of about 150 to a few hundred kilometers from the source. The presence of a lateral velocity gradient in the crust, caused by the subduction of the Cocos plate, enhances the $L g$-wave amplitude, which is then amplified further in the Mexican volcanic belt by amplification in the low-velocity volcanic rocks. Both effects lead to very large ground motions along the path from the coast to the Mexican inland, in the frequency band from 0.2 to $4 \mathrm{~Hz}$. However, for the deeper $(H=$ $40 \mathrm{~km})$, inslab, normal-faulting, 1999 Oaxaca earthquake $\left(M_{\mathrm{w}} 7.5\right)$, the amplitude of the $L g$ phase is too small to produce the abnormal wave propagation, and the direct $S$ wave and its multiple $S m S$ reflections between the free-surface and Moho show a simple attenuation with increasing distance. We compare these observations with numerical simulations of seismic-wave propagation using the Fourier spectral method. The results provide a key to the understanding of seismic-wave field generated by shallow interplate and deeper inslab earthquakes in a realistic 3D heterogeneous structure.
\end{abstract}

\section{Introduction}

Mexico suffers damage from interplate earthquakes that originate along the Pacific coast due to the subduction of oceanic plates below the continent. A recent and vivid example is the Michoacan earthquake of $1985\left(M_{\mathrm{w}} 8.0\right)$, which devastated Mexico City, killing about 20,000 people (Anderson et al., 1986). The damage during the 1985 event was not surprising since Mexico City has repeatedly been struck by coastal earthquakes in the past. During this earthquake, severe ground shaking with a predominant frequency of about $0.3 \mathrm{~Hz}$ lasted for more than $3 \mathrm{~min}$ in the lake-bed zone of Mexico City located more than $300 \mathrm{~km}$ from the plate interface. The extensive damage in the city suggests anomalous source, path, and/or site effects.

Since 1985, significant progress has been made in quantifying and understanding the causes of abnormally large ground motions recorded in Mexico City from the Michoacan earthquake in particular and interplate earthquakes in general. These include source studies (e.g., Campillo et al., 1989; Singh et al., 1988, 1990), studies on propagation effects (e.g., Singh et al., 1988; Campillo et al., 1989; Ordaz and Singh, 1992; Furumura and Kennett, 1998) and local site amplification studies (e.g., Sánchez-Sesma et al., 1988, 1993; Kawase and Aki, 1989; Chávez-García and Bard, 1994; Chávez-Garcia and Cuenca, 1996).

The Mexican mainland is also vulnerable to large, normal-faulting, inslab earthquakes that occur in the subducted ocean plate. There are many recent examples. The earthquake of 15 January $1931(M 7.8, H=40 \mathrm{~km})$ caused severe destruction to the City of Oaxaca (Barrera, 1931; Singh et al., 1985); the earthquakes of 28 August $1973\left(M_{\mathrm{w}} 7.0\right.$; $H=82 \mathrm{~km})$ and 24 October $1980\left(M_{\mathrm{w}} 7.0 ; H=65 \mathrm{~km}\right)$ resulted in deaths and damage in the states of Veracruz, Puebla, and Oaxaca (e.g., Singh and Wyss, 1976; Yamamoto et al., 1984). The recent earthquake of 15 June 1999 
$\left(M_{\mathrm{w}} 7.0, H=60 \mathrm{~km}\right)$ caused damage in the state of Puebla, especially to colonial structures in and near the city of Puebla (Singh et al., 1999). The 30 September 1999 Oaxaca earthquake $\left(M_{\mathrm{w}} 7.5 ; H=40 \mathrm{~km}\right)$ was damaging to the city of Oaxaca and many towns along the coast and between the coast and the city of Oaxaca (Singh et al., 2000b). Such severe damage of low-rise building in the towns may have been caused by higher frequency ground shaking over $3 \mathrm{~Hz}$.

There are only a few strong-motion recordings of inslab earthquakes that occurred prior to 1985. Although the seismic instrumentation has rapidly increased in Mexico beginning in 1985, significant inslab earthquake recordings only became available beginning in 1994. For this reason, the source studies of previous earthquakes were based on teleseismic recordings (e.g., Singh and Wyss, 1976; Singh et al., 1985; Gonzalez-Ruiz, 1986). The estimation of ground motion from inslab earthquakes was based on isoseismic intensities. For example, Singh et al. (1980) reported that the areas with modified Mercallii intensities (MMI) of V and VI for inslab earthquakes were significantly larger than the corresponding areas for interplate earthquakes of the same magnitude. Since the seismic intensities are related to highfrequency ground motion of over 2 or $3 \mathrm{~Hz}$, the larger MMI would imply higher stress drop during inslab earthquakes as compared to interplate earthquakes. Chávez and Castro (1988) investigated attenuation of the MMI for Mexican earthquakes and reported that at epicentral distances of less than $200 \mathrm{~km}$ the attenuation was greater for interplate earthquakes than for inslab ones. The opposite was the case at greater distances.

In the past seven years, several significant inslab earthquakes have occurred in the subducted Cocos plate below Mexico. These events were well recorded by the Mexican broadband seismograph network and the strong-motion array, permitting detailed source studies of some of these events (e.g., Mikumo et al., 1999; Quintanar et al., 1999; Hernandez et al., 2001; Iglesias et al., 2002). The data were also used to derive empirical attenuation relations (Singh $e t$ al., 2000a; Garcia et al., 2001; Iglesias et al., 2002). Pacheco and Singh (1995) analyzed waveform from broadband seismographs and strong-motion network in Mexico, which demonstrated significant differences in the amplification of seismic waves in the Valley of Mexico from interplate and inslab events. These studies capture, in a gross sense, the characteristics of the seismic-wave propagation from inslab sources but do not analyze the observed waveforms in terms of the depth of the source and its type acting in a complicated 3D crust and upper-mantle structure.

The effect of the source type and its depth on the wave propagation characteristics and the attenuation functions for both the lower- $(<0.5 \mathrm{~Hz})$ and higher- $(>3 \mathrm{~Hz})$ frequency wave field is an important issue for understanding of the strong ground motion during destructive earthquakes and for estimating the damage expected for future scenario earthquakes. The aim of this study is to understand the wave propagation and attenuation character of Mexican interplate and inslab earthquakes and to investigate the effect of 3D heterogeneous structure on the propagation of seismic wave at regional distances. In a previous article, Furumura and Kennett (1998) examined the effect of the structure of the subducted plate on the regional wave field as illustrated by the observations from the interplate 1995 Guerrero earthquake (Anderson et al., 1995) $\left(M_{\mathrm{w}} 7.3 ; H=17 \mathrm{~km}\right)$. In this study we analyze the waveforms from strong ground motion network and broadband seismographic stations of the normal-faulting, inslab 1999 Oaxaca earthquake $\left(M_{\mathrm{w}} 7.5\right.$; $H=40 \mathrm{~km}$ ) and compare them with those from the 1995 earthquake. We will focus on the difference in the character of the regional wave field from these different types of sources and study the attenuation of seismic waves as a function of frequency and source type.

To compliment the observations and gain further insights into the complicated seismic waveforms resulting from a 3D structure, we conduct numerical simulations of seismic-wave propagation using the Fourier spectral method. In the process, we demonstrate the efficiency of 3D modeling that incorporates realistic crustal and upper-mantle structure into the evaluation of strong ground motion from future scenario earthquakes.

\section{The Character of the Regional Seismic-Wave Field in Mexico}

Figure 1 displays the strong-motion accelerograph network of Mexico and the epicenters of the 1995 Guerrero earthquake $\left(M_{\mathrm{w}} 7.3\right)$ and 1999 Oaxaca earthquake $\left(M_{\mathrm{w}} 7.5\right)$, and Figure 2 illustrates the strong-motion records of radial and transverse component of velocity at rock sites along the profile from the coast to Mexico City, covering a distance range of 25 to $440 \mathrm{~km}$. The velocity seismograms were obtained by integration of filtered accelerograms with a bandpass frequency of $0.02-20 \mathrm{~Hz}$ to reduce the instrumental noise. For display, each waveform is multiplied by the epicentral distance to compensate for the geometrical spreading, thus facilitating direct observation of abnormal wave amplification and attenuation as a function of epicentral distance.

The records of the shallow, interplate, Guerrero earthquake are characterized, in most part, by large-amplitude $L g$ waves for epicentral distances beyond $150 \mathrm{~km}$. These waves travel with a wide range of group velocities, ranging between 3.2 and $2.5 \mathrm{~km} / \mathrm{sec}$ and arrive following a small-amplitude Sn phase.

It is well recognized that the $L g$ wave, as either the sum of higher-mode surface wave or of postcritical multiple $S m S$ reflections between the free surface and Moho (see e.g., Kennett, 1985; Campillo, 1990), can propagate in the crustal wave guide at longer distances with less attenuation than the other $S$ phases, such as direct $S$ wave and the mantle $S n$ wave. Therefore the $L g$ wave is usually the dominant feature at regional distances from 150 to over $1000 \mathrm{~km}$ in continental structure. The $L g$ phase is usually the prominent arrival 


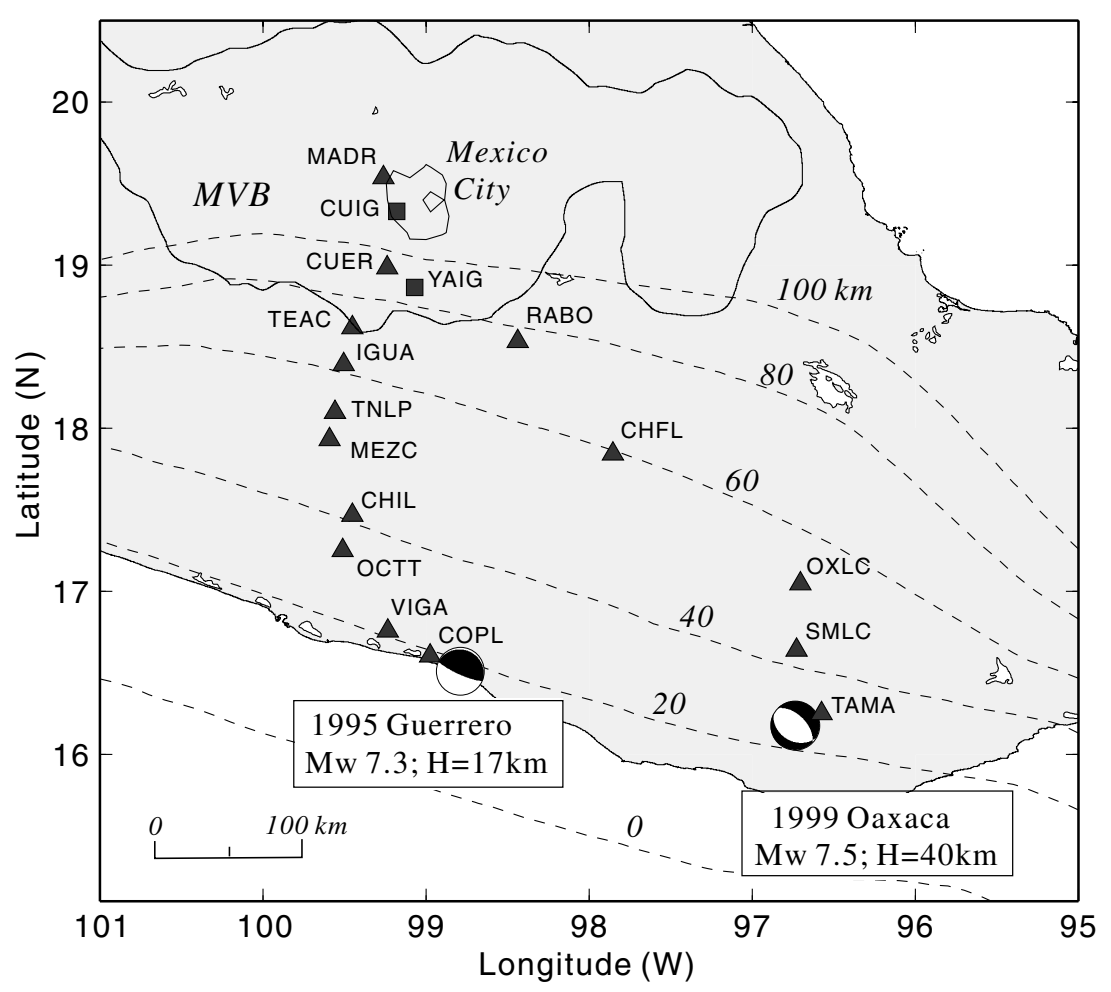

Figure 1. Map of Mexican strong-motion network and hypocenters of the 1995 Guerrero and 1999 Oaxaca earthquakes. Triangles, strong-motion stations; squares, broadband stations. The depth of the Cocos plate is shown with dashed lines. The boundary of the Mexican Volcanic Belt (MVB) and Mexico City are illustrated by a solid-line contour. in the frequency band between 0.2 and $4 \mathrm{~Hz}$ (e.g., Herrmann and Kijko, 1983). The $L g$ phase is also greatly amplified as it propagates into the Mexican Volcanic Belt (MVB), at distance of about $240 \mathrm{~km}$ from the epicenter, where low $S$-wave velocity volcanic rocks underlie the surface with an approximate thickness of $2 \mathrm{~km}$ (e.g., Shapiro et al., 1997).

The amplitude of the $L g$ wave from the deeper, normalfaulting, inslab source of the 1999 Oaxaca earthquake (Fig. 2b) is very small as compared to that of the shallow 1995 Guerrero earthquake, because quite a bit of $S$-wave energy radiates into the crustal wave guide from the deeper event. The waveform from the inslab source displays a higherfrequency $S n$ phase and larger amplitude $S m S$ reflections at some distances. The large amplitude $S m S$ phases are more distinctly seen on the transverse component.

Compared with the 1995 Guerrero event, the length of the $S$-wave coda of the inslab earthquake is very short. Even at MVB sites (e.g., stations YAIG, CUIG) the amplitude and length of the $S m S$ phases remain unchanged. Consequently, the amplitude of the $S$ wave from this event decays simply with increasing distances.

The empirical spectral attenuation of seismic waves from interplate and inslab Mexican earthquakes has been studied by Ordaz and Singh (1992) and Garcia et al. (2001), respectively. The recordings at stations located in MVB were excluded from the analysis in both of these studies. The spectral attenuation function, $\Gamma(f, R)$, of the intense part of the ground motion can be described by

$$
\Gamma(f, R)=\mathrm{e}^{-\pi f R / V_{s} Q(f)} / G(R)
$$

where $f$ is the frequency, $R$ is the hypocentral distance, $Q$ is the anelastic attenuation coefficient, $V_{\mathrm{s}}$ is the shear-wave velocity, and $G(R)$ is the geometrical spreading term. For interplate earthquakes, Ordaz and Singh (1992) assumed $V_{\mathrm{s}}$ $=3.5 \mathrm{~km} / \mathrm{sec}, G(R)=R$ for $R \leq 100 \mathrm{~km}$, and $G(R)=$ $(100 R)^{1 / 2}$ for $R>100 \mathrm{~km}$, and found $Q(f)=273 f^{0.66}$. For inslab events, Garcia et al. (2001) assumed $V_{\mathrm{s}}=4.5 \mathrm{~km} / \mathrm{sec}$ and $G(R)=R$ for all distances and reported $Q(f)=276$ $f^{0.57}$. The attenuation function is nearly the same for both types of earthquakes in the distance $(R<500 \mathrm{~km})$ and the frequency range of interest in this study $(0.3 \leq f \leq 4 \mathrm{~Hz})$.

Figure 3 compares the spectral attenuation of the horizontal ground motion from the 1995 Guerrero and the 1999 Oaxaca earthquakes at 0.5 and $4 \mathrm{~Hz}$. An empirical attenuation function of Ordaz and Singh (1992) for shallow subduction earthquakes of Mexico and Garcia et al. (2001) is also illustrated in the figure.

For the 1995 Guerrero earthquake the spectral attenuation at $0.5 \mathrm{~Hz}$ (Fig. 3a) shows a large discrepancy between the observations and the empirical attenuation function at distances beyond $200 \mathrm{~km}$ from the epicenter. As we have seen in Figure 2, this difference arises, mostly, from the dominance of $L g$ phase in this frequency band and an additional amplification in the MVB. As mentioned previously, Ordaz and Singh (1992) excluded the data from MVB sites in the derivation of the empirical attenuation function. Thus the deviation of the observed data in the MVB from the empirical attenuation function for frequency of $0.5 \mathrm{~Hz}$ provides a measure seismic-wave amplification at these sites. The character of anomalous wave propagation in the MVB from 
(a)
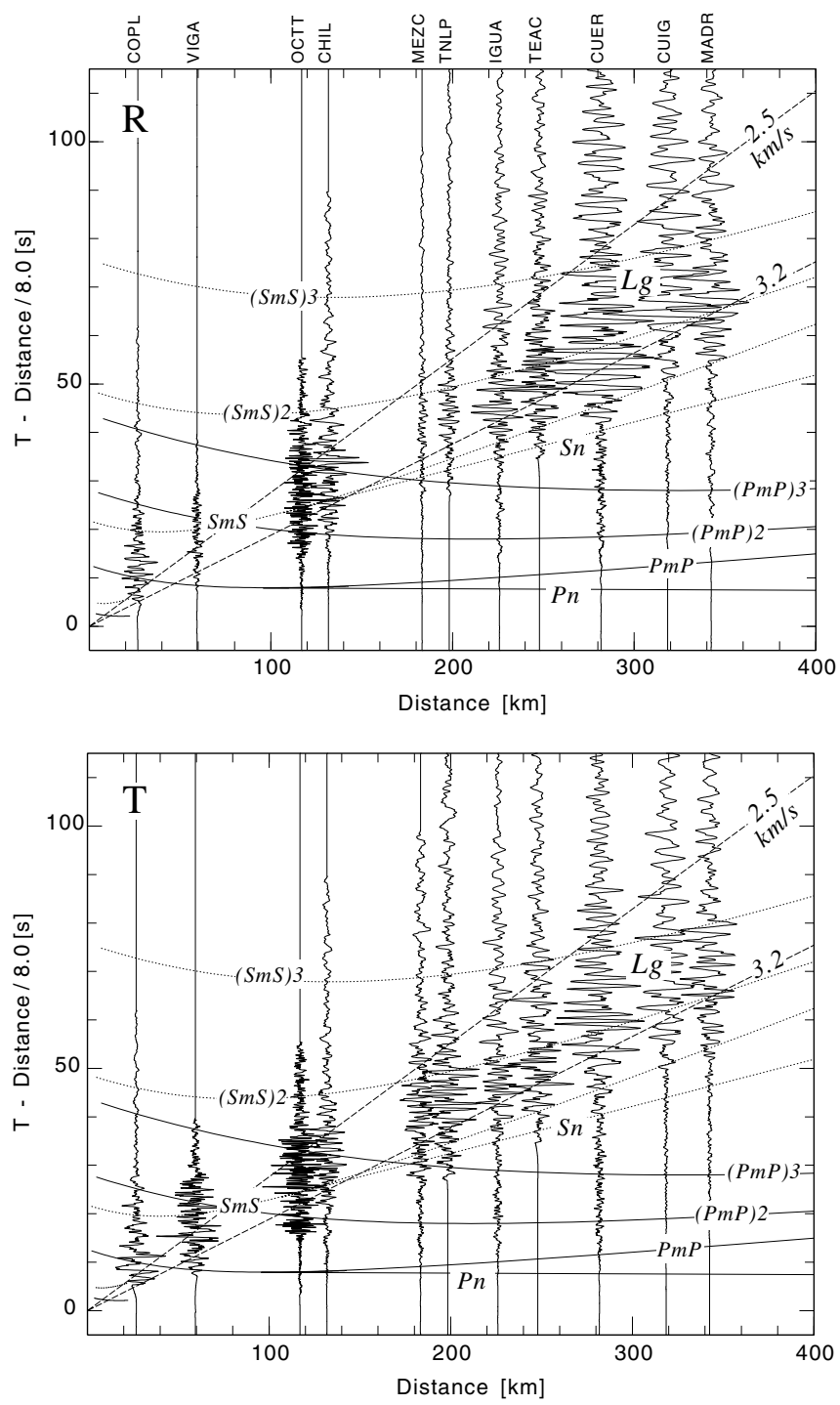

(b)
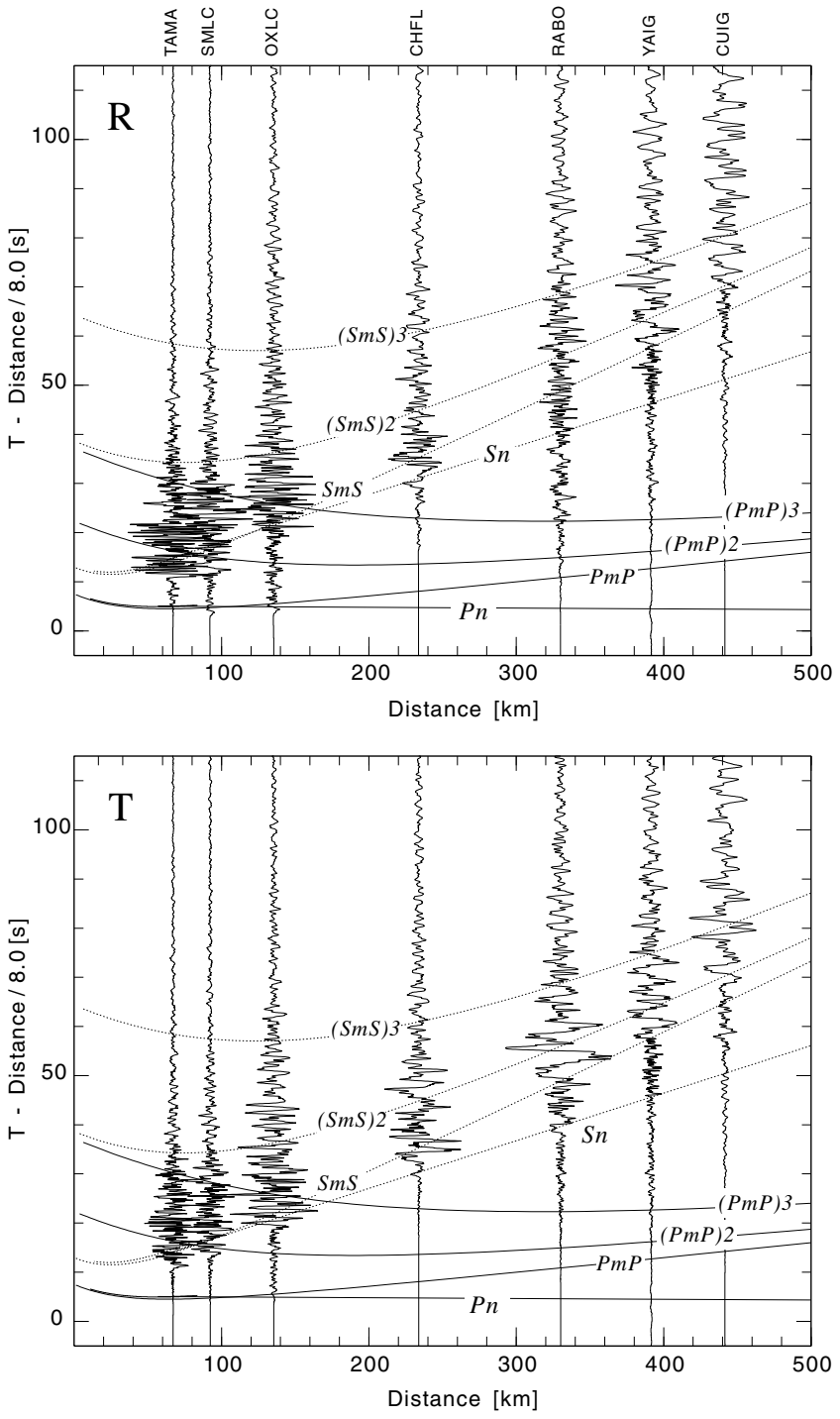

Figure 2. Record sections of transverse-component ( $\mathrm{T}$ ) and radial-component (R) of ground velocity for the (a) 1995 Guerrero earthquake $(H=17 \mathrm{~km})$ and (b) 1999 Oaxaca earthquake $(\mathrm{H}=40 \mathrm{~km})$. The amplitude of each record is multiplied by the epicentral distance. The travel-time curves for a stratified reference model for Mexico are superimposed on the records. Major phases are marked.

the shallow Mexican subduction zone earthquakes has been discussed by Ordaz and Singh (1992), Singh et al. (1995) and Cárdenas et al. (1998) and is considered to be the cause of the large and long duration of ground motion at Mexico City during the damaging earthquake (Cárdenas et al., 1997; Shapiro et al., 1997; Furumura and Kennett, 1998; Iida, 1999).

At the higher frequency of $4 \mathrm{~Hz}$, the amplitude of both interplate and inslab earthquakes decays monochromatically with increasing distances, which are in good agreement with the corresponding empirical attenuation functions, although there is large scatter in the observation data of the interplate earthquake. The amplitude of the $L g$ phase at this frequency is too small to produce the abnormal wave propagation as we have seen in the $0.5-\mathrm{Hz}$ wave field. We can find some localized ground amplitude at distances of about 100 and $280 \mathrm{~km}$ from the epicenter caused by the first and second arrivals of wide-angle $\mathrm{SmS}$ reflections.

\section{D Simulation of Seismic-Wave Propagation}

To understand the character of the observed recordings during the 1995 Guerrero and the 1999 Oaxaca earthquakes and to examine the influence of the source depth and its type and the structure of the Mexican subduction zone on the features of the seismic-wave field, we conduct 2D numerical 
(a)

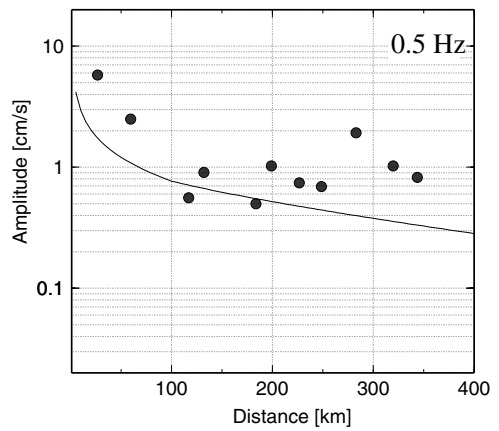

(b)
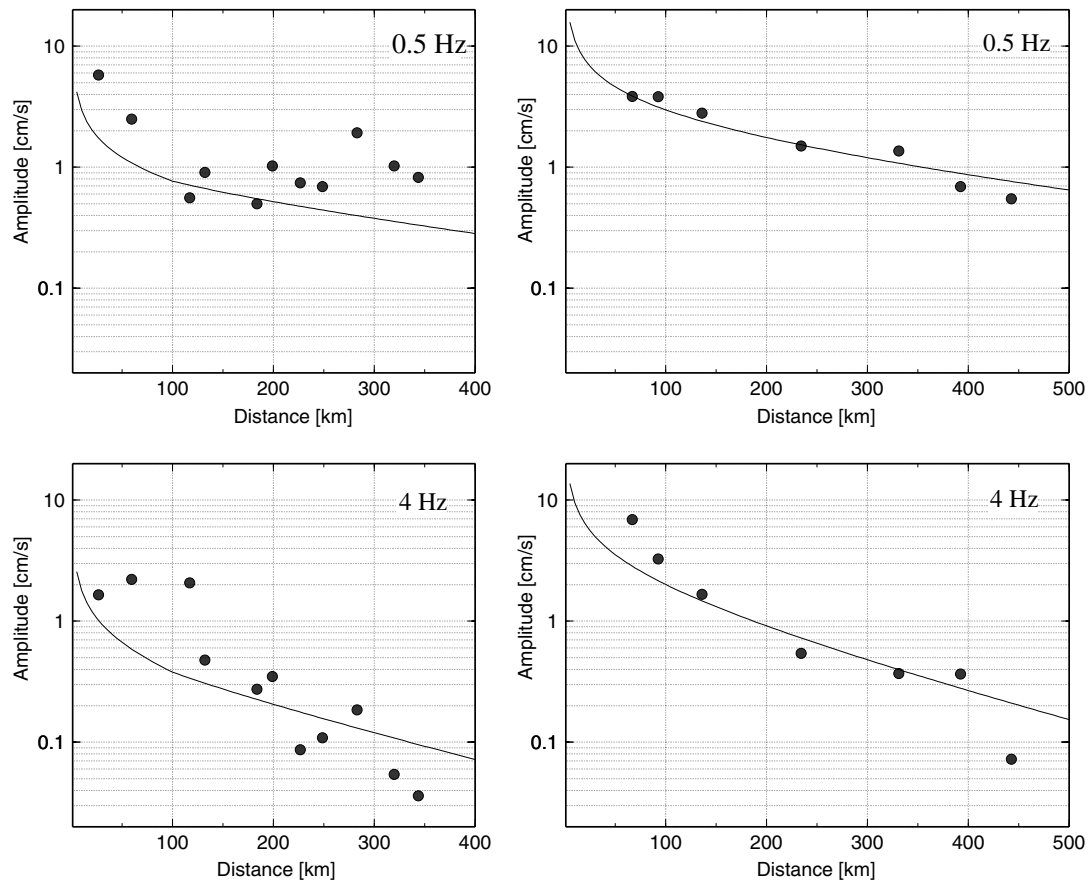

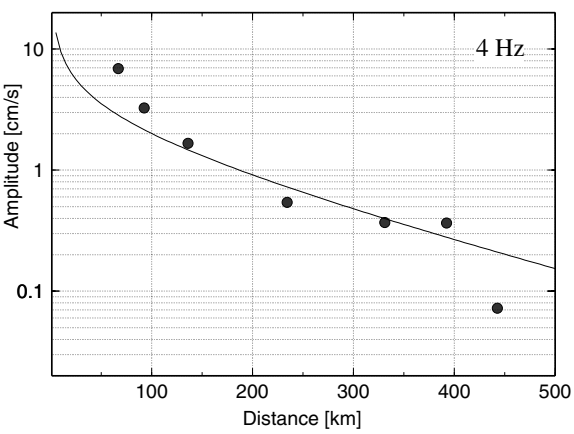

Figure 3. Spectral attenuation of horizontal ground motion as a function of hypocentral distance for the (a) 1995 Guerrero earthquake $(H=17 \mathrm{~km})$ and (b) 1999 Oaxaca earthquake $(H=40 \mathrm{~km})$ at (top) $0.5 \mathrm{~Hz}$ and at (bottom) $4 \mathrm{~Hz}$. The continuous lines represent the empirical spectral attenuation function for $S$ waves (see text). simulations using the Fourier spectral method (e.g., Kosloff et al., 1984; Furumura and Takenaka, 1996).

In the simulations, we use a crustal and upper-mantle structure of the Mexican subduction zone that includes the Cocos plate descending beneath Mexican mainland with an average dip angle of $10^{\circ}$. The model is adopted from the works of Valdes et al. (1986) and Valdes and Meyer (1996), which are based on an analysis of reflection experiment and gravity data. The subducted plate consists of a two-layer, 6-km-thick oceanic crust with relatively low-velocity and high-attenuation material, overlaying a higher-velocity and low-attenuation oceanic mantle. The thickness of the lithosphere is $30 \mathrm{~km}$ (Table 1). We have included surface topography with a maximum height of $2 \mathrm{~km}$ above the sea level and a 2-km-thick superficial layer to represent the MVB with slow shear-wave velocity $\left(V_{\mathrm{s}}=2.0 \mathrm{~km} / \mathrm{sec}\right)$ and a quality factor for $S$ wave of 150 .

The model covers an area of $512 \mathrm{~km}$ in length and 128 $\mathrm{km}$ in depth, which is discretized at a uniform grid spacing of $0.25 \mathrm{~km}$, with a 20-grid points buffer zone of Cerjan et al. (1985) in the surrounding area to minimize artificial reflections at the boundaries.

This 2D simulation is valid for frequencies up to $4 \mathrm{~Hz}$, which is four times higher than the previous experiments (Furumura and Kennett, 1998).

We have used a low-angle thrust-fault source at a depth of $17 \mathrm{~km}$ to represent the 1995 Guerrero earthquake source and a normal-faulting source at a depth of $40 \mathrm{~km}$ for the 1999 Oaxaca earthquake. The source time function is a pseudodelta function (Herrmann, 1979), which imparts seismic waves with a maximum frequency of $4 \mathrm{~Hz}$.
Table 1

Model Parameters Used in the 3D Simulation

\begin{tabular}{lccccc}
\hline & $\begin{array}{c}V_{p} \\
(\mathrm{~km} / \mathrm{sec})\end{array}$ & $\begin{array}{c}V_{s} \\
(\mathrm{~km} / \mathrm{sec})\end{array}$ & $\begin{array}{c}\rho \\
\left(\mathrm{t} / \mathrm{m}^{3}\right)\end{array}$ & $Q$ & $\begin{array}{c}\text { Thickness } \\
(\mathrm{km})\end{array}$ \\
\hline \multicolumn{5}{c}{ Mexican Mainland } \\
Layer 1 (MVB) & 4.0 & 2.0 & 2.0 & 150 & $0.0-2.5$ \\
Layer 2 & $5.2-5.3$ & $3.0-3.1$ & $2.2-2.3$ & 200 & $0.6-8.0$ \\
Upper crust & $5.5-5.8$ & $3.2-3.4$ & $2.4-2.5$ & 400 & $4.9-12.6$ \\
Lower crust & $6.4-7.1$ & $3.7-4.1$ & $2.7-2.9$ & 600 & $11.5-29.8$ \\
Upper mantle & $8.2-8.4$ & $4.7-4.8$ & $3.2-3.2$ & 800 & - \\
& \multicolumn{7}{c}{ Cocos Plate } \\
Oceanic crust & $5.0-7.0$ & $2.8-3.9$ & $2.1-2.8$ & $100-150$ & 3.0 \\
Oceanic basalt & $6.8-7.1$ & $3.8-3.9$ & $2.8-2.9$ & $150-200$ & 3.0 \\
Oceanic mantle & $8.2-8.6$ & $4.7-4.9$ & $3.2-3.3$ & 1000 & 24.0 \\
\hline
\end{tabular}

\section{Interplate Thrust-Faulting Source}

Wave-field snapshots of $P$ and $S V$ waves and synthetic seismograms of radial-component ground motion for the interplate earthquakes are displayed in Figure 4a.

In the upper snapshot frame $(6 \mathrm{sec})$ we see the radiation of $P$ and $S$ waves from the source on the boundary between the subducted plate and the continental lower crust. The $S$ wave, with an incidence angle greater than $35^{\circ}$ at the free surface, is totally reflected back into the crust ( $24 \mathrm{sec})$. The shallow-dipping subducted Cocos plate also acts as an efficient reflector for the $S$ wave, which leads to clear multiple $S$-wave reverberations between the free surface and the dipping plate. By $54 \mathrm{sec}$, a well-developed $L g$-wave train, as the sum of postcritical $S m S$ reflections between the free surface and Moho (or the subducting plate), is clearly seen in 
(a)
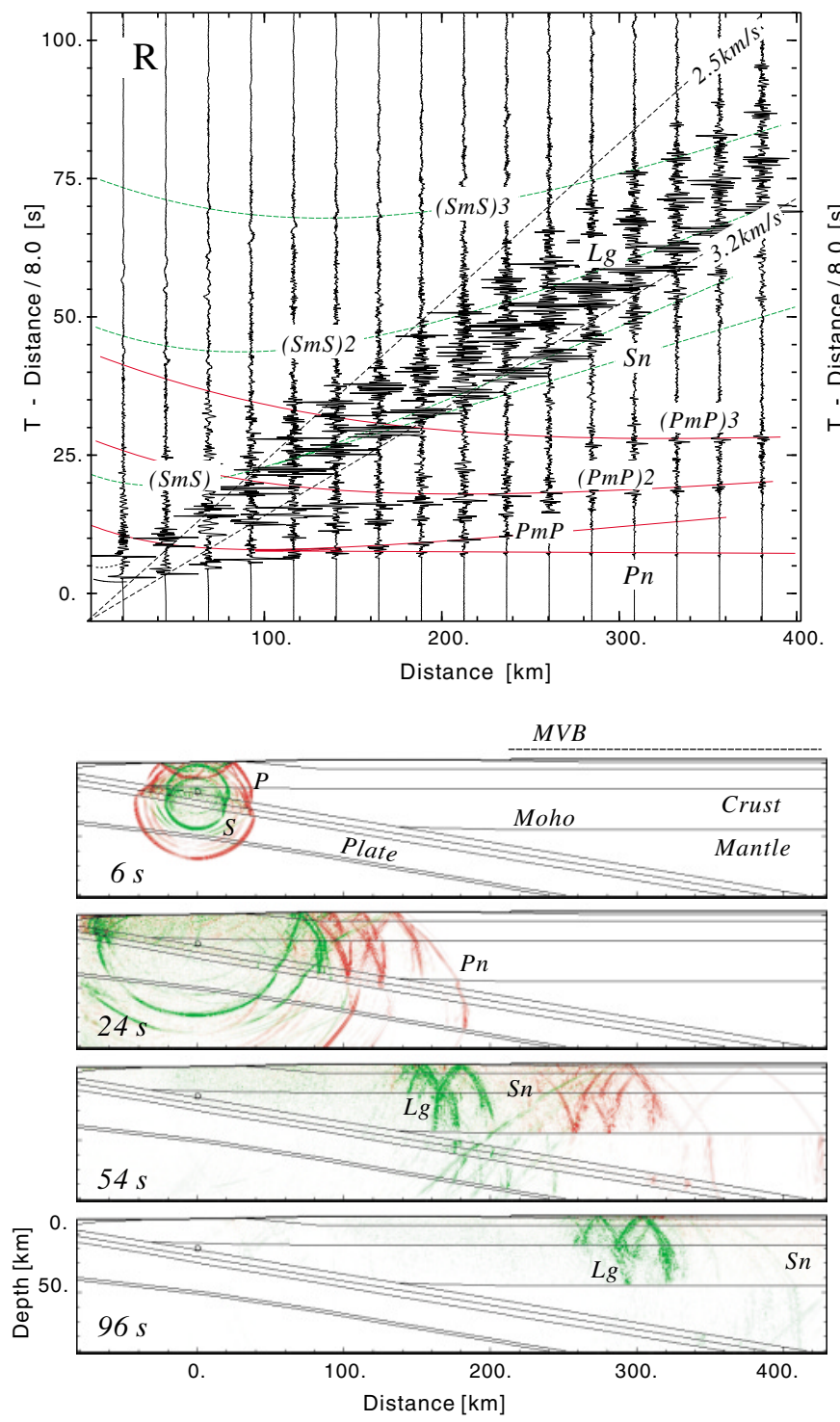

(b)
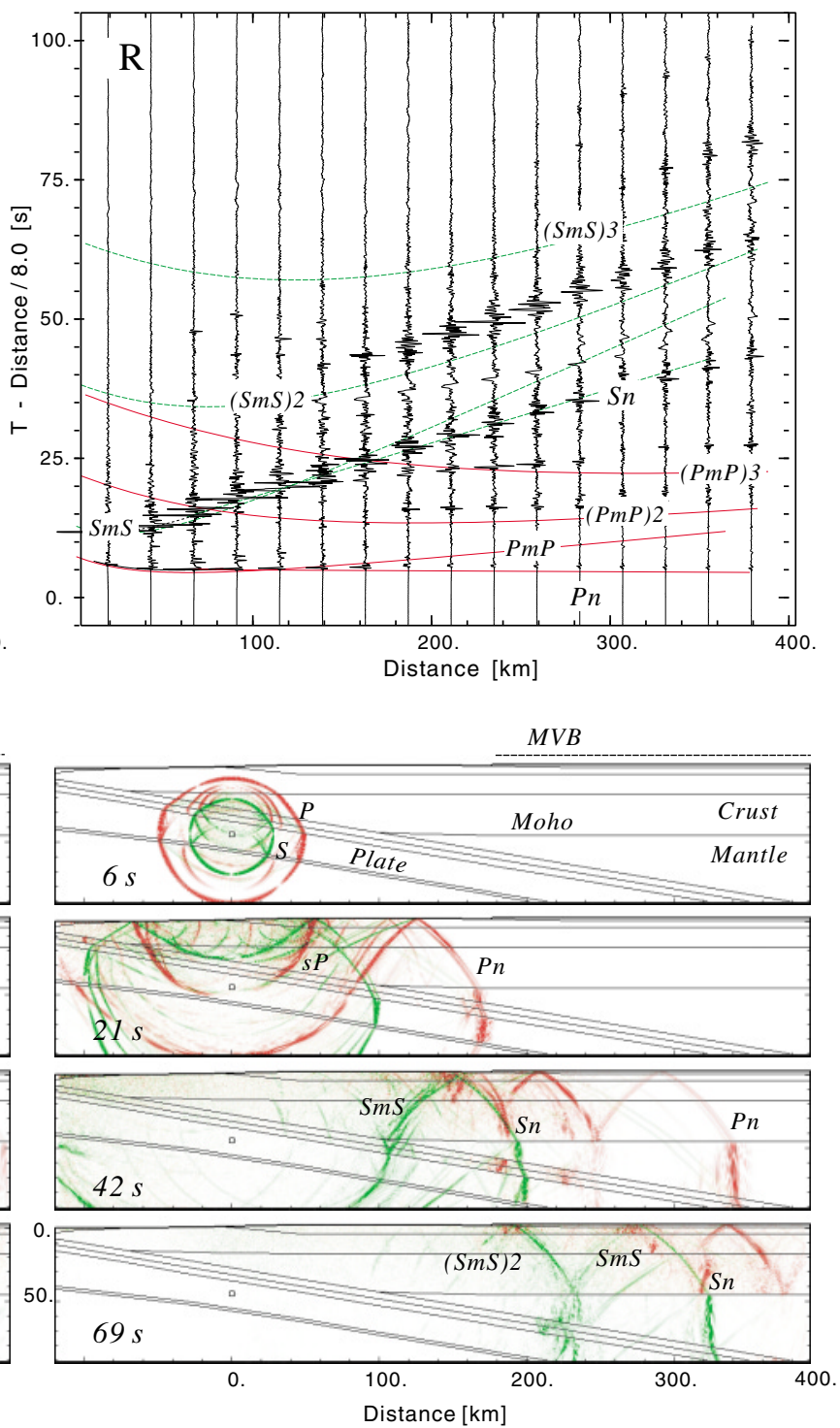

Figure 4. Synthetic velocity seismograms for the radial component of ground motion and snapshots of seismic-wave field calculated from 2D numerical modeling for the (a) interplate thrust-faulting event $(H=17 \mathrm{~km})$ and (b) inslab normal-faulting event $(H=40 \mathrm{~km})$. The $P$ wave is shown in red, and the $S$ wave is shown in green. The travel-time curves for a stratified reference model are superimposed on the record section, and major phases are marked.

the crust. We can observe trapped $S$-wave energy propagating in the crustal wave guide, which travels long distances without attenuation $(96 \mathrm{sec})$. We can also note multiple $S$ wave reflections between the free-surface and midcrustal interface (i.e., the Conrad discontinuity), so that the sum of these reflections produces a dense $\mathrm{V}$-shape wave train propagating in the crust $(96 \mathrm{sec})$.

Synthetic seismograms of the radial-component ground velocity for the shallow interplate event are displayed in Figure $4 \mathrm{a}$, where regular pattern of multiple $S m S$ and Conrad reflections are clearly seen at distances over $150 \mathrm{~km}$. The
$L g$-wave train arrives with a group velocity between 3.2 and $2.5 \mathrm{~km} / \mathrm{sec}$, in good agreement with the observations (Fig. 2a). The amplitude of the $S n$ head wave is too weak to discern in the seismograms, which also agrees with the observations. The weak mantle $S n$ phase is in consequence of small fraction of $S$-wave energy leaking from the crust to the mantle.

\section{Inslab Normal-Faulting Source}

Snapshots of seismic-wave field and synthetic seismograms for an inslab earthquake, displayed in Figure 4b, show 
a markedly different pattern of seismic-wave field as compared to that for the shallow source.

In the first frame of the snapshots $(6 \mathrm{sec})$, we see the radiation of the $S$ wave from the source inside the plate. The $S$ wave impinges upon the free surface with a small incidence angle of about $10^{\circ}$ at a distance around $30 \mathrm{~km}$ from the epicenter and causes large ground oscillations there. The small angle of incidence of $S$ wave at the free surface produces very large $S$ to $P$ conversion, which dramatically weakens the $S$-wave reflections $(21 \mathrm{sec})$. The $S$ phase is further weakened on reflection from the subducting plate and the Moho, most of the energy leaking into the mantle (42 sec, $69 \mathrm{sec})$. Thus, the reverberating $S m S$ phase in the crust decreases dramatically in amplitude with propagation through the leaking of energy into the mantle.

The change in the character of regional seismic-wave field as a result of increasing source depth is also clearly seen in the synthetic seismograms (Fig. 4b). For instance, $S n$ arrivals are large in the distance range of $120-400 \mathrm{~km}$, with increasing relative amplitudes at larger distances. There are clear multiple $S m S$ reflections in the seismograms with a 15-sec interval between phases. Reflections at the Conrad are very weak for the $40-\mathrm{km}$-depth source. The amplitude of seismic waves decays in a relatively simple manner with increasing epicentral distance.

Decay Function for Interplate and Inslab Earthquakes

Figure 5 displays decay functions of horizontal motion derived from the 2D simulations of the thrust-fault, interplate earthquake and a normal-fault, inslab event at frequencies 0.5 and $4 \mathrm{~Hz}$. The empirical attenuation functions of Ordaz and Singh (1982) and Garcia et al. (2001) for interplate and inslab earthquakes, respectively, are superimposed on the figure.

As we have seen in the observed seismograms, there is significant difference in the attenuation for the two types of earthquakes, especially at $0.5 \mathrm{~Hz}$ where the $L g$ wave dominates. For shallow, interplate earthquakes, the peak ground velocity starts increasing at distances beyond $200 \mathrm{~km}$ from the epicenter. The peak amplitude at $320 \mathrm{~km}$ is roughly three times greater than the predicted amplitude from the empirical attenuation function. This observation is in agreement with the results of Ordaz and Singh (1992). The simulated waveforms from the normal-faulting inslab earthquake show larger amplitude at shorter distance $(<120 \mathrm{~km})$ and slightly larger attenuation than average at longer propagation distances at $0.5 \mathrm{~Hz}$.

At the higher frequency of $4 \mathrm{~Hz}$, the amplitudes for both types of earthquakes decay in a simpler manner with increasing distance than at $0.5 \mathrm{~Hz}$. The simulation result agrees with the observation reasonably well, although there is large scatter in the observed high-frequency $(4 \mathrm{~Hz})$ wave field from the interplate earthquake. Localized amplification at distances of 100 and $280 \mathrm{~km}$ from epicenter caused by an arrival of wide-angle $\operatorname{SmS}$ reflections is also simulated quite well.
Figure 5 provides a possible explanation for the observation of Chávez and Castro (1988). Because of the bump in the attenuation curve for interplate earthquakes beginning about $200 \mathrm{~km}$ caused by the amplification in the MVB and large amplitude $S m S$ phases, the attenuation rate changes around this distance. Thus, the attenuation from interplate earthquakes appears slower beyond about $200 \mathrm{~km}$. This is not the case for inslab earthquakes.

Figure 6 compares the Fourier spectra computed from synthetic seismograms at epicentral distances of 40,120, and $320 \mathrm{~km}$. At $40 \mathrm{~km}$, the Fourier amplitude from the inslab earthquake is greater than from the interplate event. However, as the epicentral distance increases, the Fourier amplitudes of the shallow interplate earthquake increase gradually in the lower frequency band of $0.3-4 \mathrm{~Hz}$. At the epicentral distance of $320 \mathrm{~km}$, the amplitude from the interplate earthquake is almost 10 times greater than that for the inslab earthquake in this frequency band.

This figure demonstrates that the heterogeneous crustal structure of the Mexican mainland, which is characterized by subducted Cocos plate and shallow structure of the MVB, acts a good propagator for $S$ waves in the frequency band of $0.3-4 \mathrm{~Hz}$ for the shallow interplate earthquakes.

\section{D Simulation of Mexican Earthquakes}

We conducted 3D simulation of seismic-wave propagation from the two Mexican earthquakes to compliment the results of the 2D modeling and to study the character of wave propagation in realistic 3D heterogeneous structure of Mexican mainland.

We employ a Fourier spectral method (PSM) finitedifference method (FDM) hybrid simulation code (Furumura et al., 2000, 2002) for large scale 3D simulation using parallel computers. This combines the Fourier spectral method (PSM) in the calculation of seismic-wave field in the horizontal $(x, y)$ coordinates with the fourth-order finite-difference method (FDM) in the vertical $(z)$ coordinate. The accurate PSM calculation allows large-grid discretization in the horizontal direction, and the localized FDM calculation minimizes the demand for the interprocessor communication for the parallel computing as compared to the conventional parallel PSM (e.g., Reshef et al., 1988; Furumura et al., 1998; Furumura and Koketsu, 2000). Therefore, the parallel PSM/ FDM hybrid method offers high parallel performance for large-scale 3D simulation using a large number of processors.

The simulation model is $512 \mathrm{~km}$ by $512 \mathrm{~km}$ by $104 \mathrm{~km}$, which is discretized with a uniform grid size of $1 \mathrm{~km}$ in the horizontal direction and $0.5 \mathrm{~km}$ in the vertical direction. The subsurface structure is based on the $V_{\mathrm{p}}$ and the density ( $\rho$ ) structure derived by refraction experiments and gravity data (Valdes et al., 1986; Valdes and-Meyer, 1996), the $V_{\mathrm{s}}$ structure estimated from the surface wave (Campillo et al., 1996; Shapiro et al., 1997), the quality factor $(Q)$ from spectral attenuation of $S$ and $L g$ waves (Castro et al., 1994; Cárdenas 
(a) Interplate source $(\mathrm{H}=17 \mathrm{~km})$
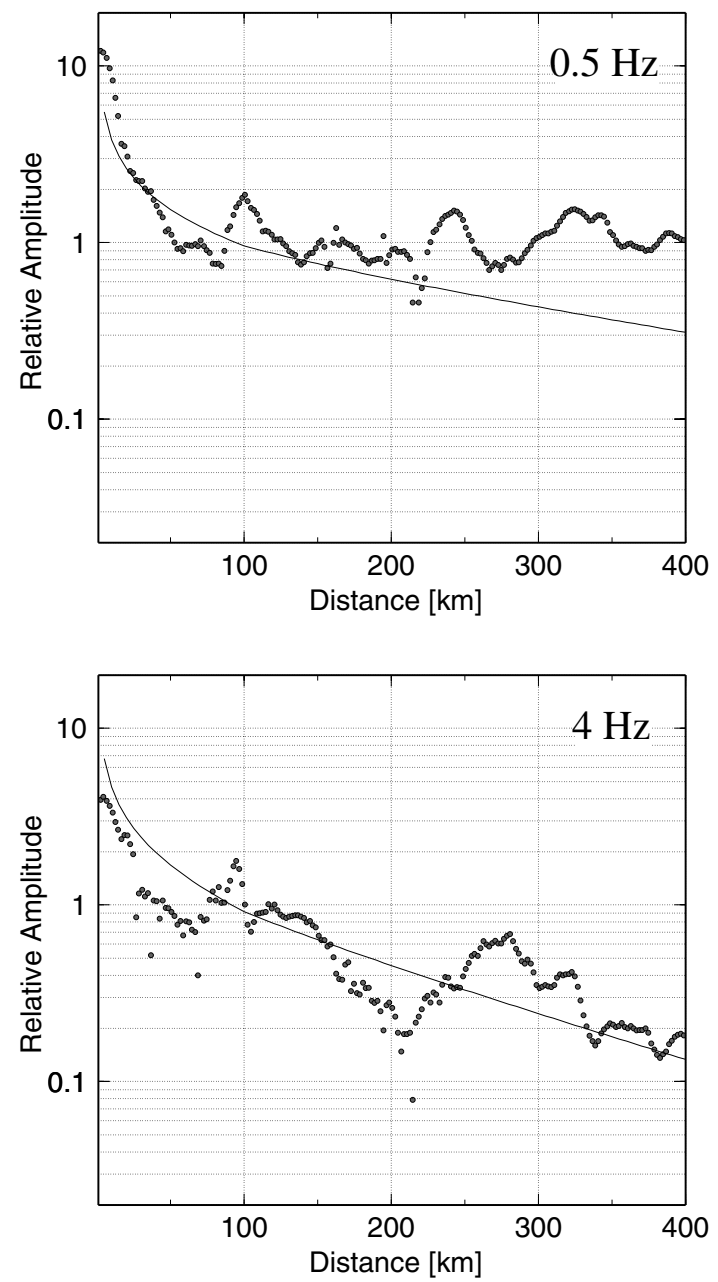

(b) Inslab source $(\mathrm{H}=40 \mathrm{~km})$
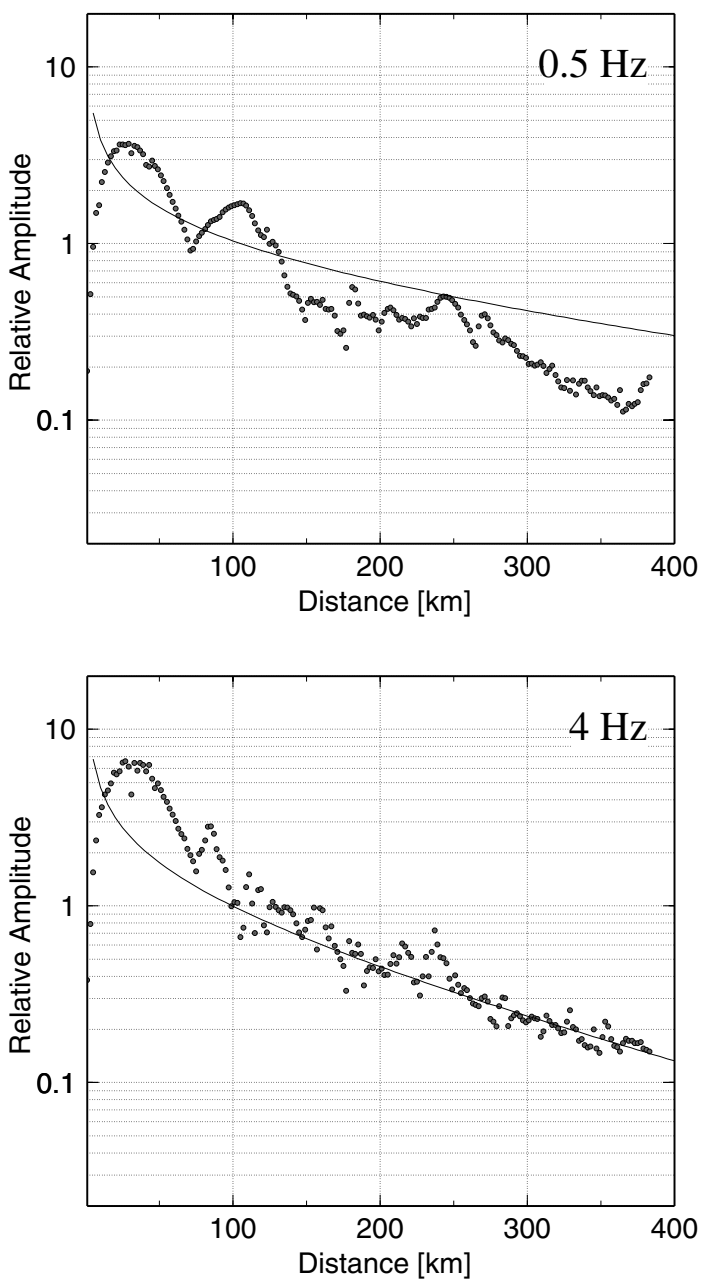

Figure 5. Attenuation of simulated peak amplitude of ground velocity as a function of epicentral distance and frequency from the modeling of (a) interplate thrust-faulting event $(\mathrm{H}=17 \mathrm{~km})$ and (b) inslab normal-faulting event $(\mathrm{H}=40 \mathrm{~km})$ at frequency of (top) $0.5 \mathrm{~Hz}$ and (bottom) $4 \mathrm{~Hz}$. The amplitude is normalized to the same value at $100 \mathrm{~km}$.

et al., 1997; Ottemöller et al., 2002), and the depth of subducted plate from hypocentral data (Pardo and Suárez, 1995; Kostoglodov et al., 1996). The shape of Moho is derived from the surface topography by assuming $80 \%$ isostatic compensation and that the Moho surface is smooth. The model is shown in Figure 7.

We assigned lower velocity $\left(V_{\mathrm{p}}=4.4 \mathrm{~km} / \mathrm{sec} V_{\mathrm{s}}=2.0\right.$ $\mathrm{km} / \mathrm{sec})$ and slightly larger attenuation $(Q=150)$ to the 2-km-thick volcanic rocks of the MVB. We assigned a relatively faster velocity for the water layer of $V_{\mathrm{p}}=2.2 \mathrm{~km} / \mathrm{sec}$ and $V_{\mathrm{s}}=0 \mathrm{~km} / \mathrm{sec}$ and $Q=200$, because the velocity of water layer is too slow to include in the simulation model. The model includes an accretionary prism along the trench, which has low velocity $\left(V_{\mathrm{p}}=4.4 \mathrm{~km} / \mathrm{sec} V_{\mathrm{s}}=2.2 \mathrm{~km} / \mathrm{sec}\right)$, a high attenuation $\left(Q_{\mathrm{s}}=50\right)$, a width of about $40 \mathrm{~km}$, and a maximum thickness of about $4 \mathrm{~km}$. Surface topography is not included in the simulation model.
The minimum $S$-wave velocity of the superficial layer in the $3 \mathrm{D}$ model is $2.0 \mathrm{~km} / \mathrm{sec}$, so that with sampling of two grid points per shortest wavelength in the horizontal coordinate and four grid points in the vertical coordinate, the PSM/FDM hybrid method can simulate seismic-wave propagation for frequencies below $1 \mathrm{~Hz}$. The 3D simulation took a memory of 8 Gbyte and a wall-clock time of $9 \mathrm{hr}$ using 32 processors of a Fujitsu VPP700E vectorized parallel computer for calculating wave propagation for $210 \mathrm{sec}$ through 7000 time-step computations.

\section{The 1995 Guerrero Earthquake}

The fault-slip model for the 1995 Guerrero earthquake we use here is derived from an inversion of strong-motion data (Courboulex et al., 1997). The slip distribution shows two branches aligned toward the south and east, and maximum slip of over $3 \mathrm{~m}$ occurs $10 \mathrm{~km}$ south of the hypocenter 
(a)

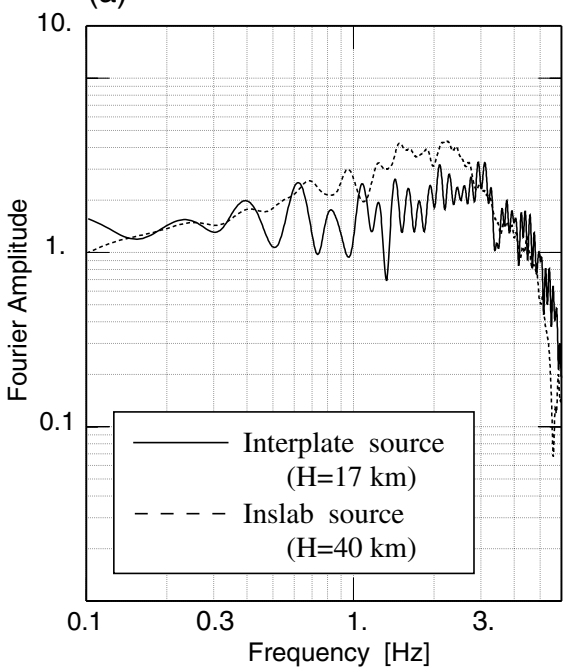

(b)

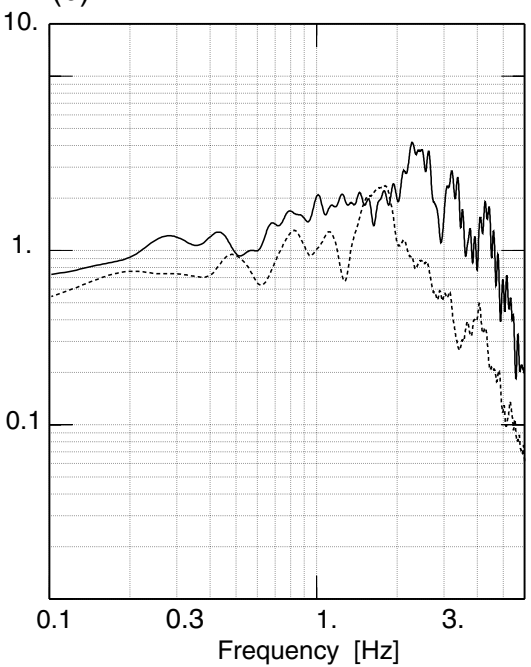

(c)

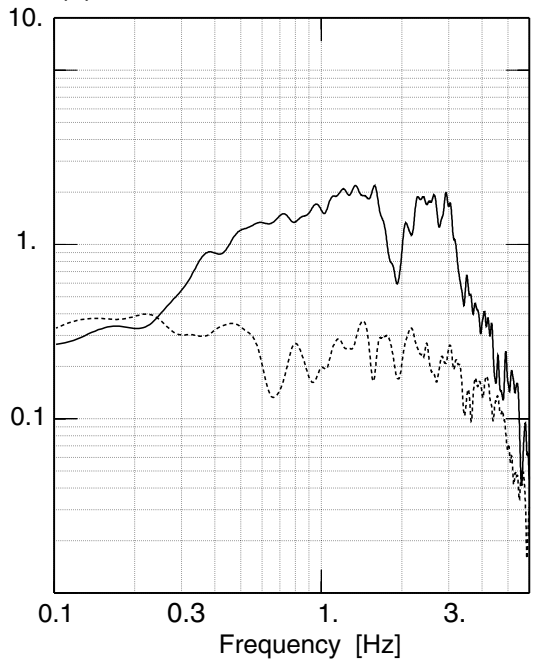

Figure 6. Comparison of Fourier amplitude spectra of simulated waveforms for the shallow $(H=17 \mathrm{~km})$ thrust-faulting event (solid line) and deeper $(H=40 \mathrm{~km})$ inslab normal-faulting event (dashed line) at epicentral distance of (a) $40 \mathrm{~km}$, (b) $120 \mathrm{~km}$, and (c) $320 \mathrm{~km}$.

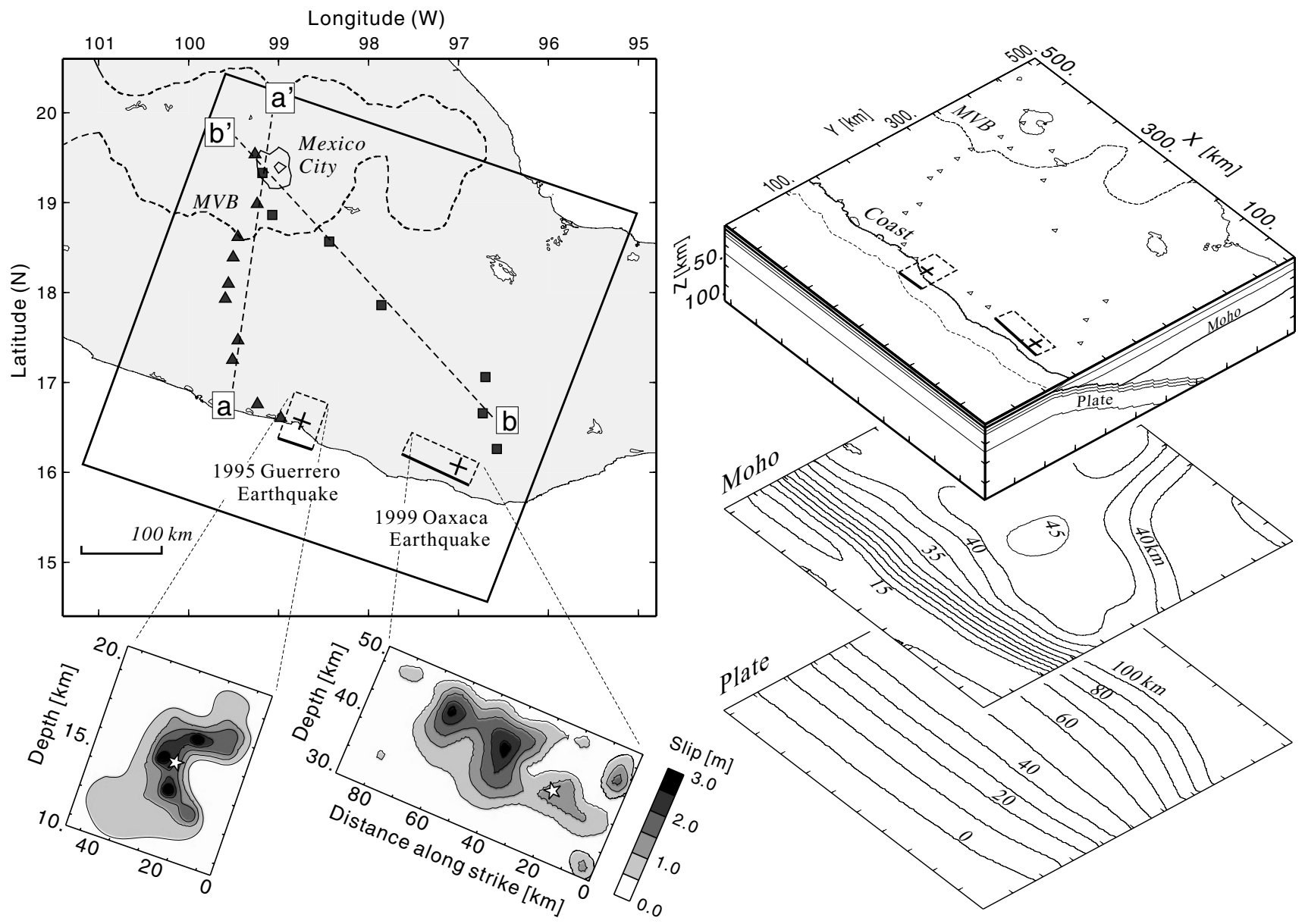

Figure 7. Structural model for Mexico showing configuration of the Moho discontinuity and the Cocos plate. Source-slip model for the 1995 Guerrero (Courboulex et al., 1997) and the 1999 Oaxaca earthquakes (Hernandez et al., 2001) are also displayed. 
at the southern branch. The ruptures propagate bilaterally from the center with a rupture velocity of $2.5 \mathrm{~km} / \mathrm{sec}$ (Courboulex et al., 1997).

To allow smooth fault rupture propagation, the fault plane is divided into 450 patches of size $2.5 \mathrm{~km} \times 2.5 \mathrm{~km}$ by linear interpolation, and a double-couple point source is assigned to each subfault. The source-time history of each point source is a pseudodelta function (Herrmann, 1979) with a dominant period of $1 \mathrm{sec}$. The total seismic moment is $M_{0}=1.31 \times 10^{20} \mathrm{~N} \mathrm{~m}$.

Figure 8a shows a set of snapshots of the horizontal ground velocity. In the first frame $(21 \mathrm{sec})$ a large amplitude $S$ wave radiates from the source, and in the second frame $(44 \mathrm{sec})$, an $S n$ wave propagates to a distance of about 200 $\mathrm{km}$ from the epicenter. The sequence of multiple $\mathrm{SmS}$ reflections between the free surface and Moho produce large amplitude $L g$ phase; the duration of $L g$-wave train increases as it propagates inland to the Mexican mainland $(67 \mathrm{sec})$. The $L g$ phase tends to reduce its propagation speed on entering the MVB and acquires a large amplitude through the amplification effect of the low-velocity superficial layer (99 sec).

Synthetic velocity seismograms for the radial and transverse components along the station profile of $\mathrm{aa}^{\prime}$, which lies close to the recording stations shown in Figure 1, are displayed in Figure 9a. In Figure 10 we display the distribution of the peak ground acceleration (PGA) of the horizontal motion. Larger values of PGA from the source toward inland are clearly seen in Figure 10. These results, in large part, come from the propagation of the $L g$ wave and its local amplification in the MVB. The pattern of anomalous inland amplification of PGA agrees well with the observed PGA, although the coverage of strong-motion stations to the southeast of Mexico City is not dense enough to produce a detailed distribution of PGA during the earthquake. We compare the simulated and observed PGA values with that expected from an empirical function of Ordaz and Singh (1989) for interplate Mexican earthquakes in Figure 11. This function is derived from extensive hard-rock site strongmotion recordings (Ordaz and Singh, 1989). The simulated PGA values are in good agreement with the corresponding empirical function for hard-rock stations. Larger PGA values at MVB stations also agree well with observations.

\section{The 1999 Oaxaca Earthquake}

Figure $8 \mathrm{~b}$ shows the snapshots of horizontal velocity from the 3D simulation of the 1999 Oaxaca earthquake, and Figure 9b illustrates the corresponding synthetic seismograms along a profile of $b^{\prime}$ ' in Figure 7, close to the station profile in Figure 2.

We used the fault rupture model of Hernandez et al. (2001) derived from an inversion using near-source strongmotion records. The slip distribution on the fault shows two areas of $2.5-\mathrm{m}$ peak slip located about $20 \mathrm{~km}$ and $40 \mathrm{~km}$ northwest of the hypocenter at a depth of about $45 \mathrm{~km}$.

In this calculation the fault rupture is approximated by
630 double-couple point sources arranged on the fault plate with an interval of $2.7 \mathrm{~km}$, and the rupture propagates almost unilaterally from the epicenter to the northwest with a rupture velocity of about $2.7-3.0 \mathrm{~km} / \mathrm{sec}$ (Hernandez et al., 2001). Total moment for this earthquake is $M_{0}=1.7 \times$ $10^{20} \mathrm{~N} \mathrm{~m}$.

The snapshot of the seismic-wave field from the deeper source of the 1999 Oaxaca earthquake shows simple characteristics as compared with that from the shallow, thrustfaulting 1995 Guerrero earthquake (Fig. 8). The simulated PGA distribution shows a relatively simple decay with distance with multiple localized zones of high amplitudes about 200 and $400 \mathrm{~km}$ from the epicenter. These zones are produced by arrival of multiple $S m S$ reflections (Fig. 10b). The amplification at the MVB is insignificant for the vertical incidence of these $S$ phases from the deeper inslab source.

We compare the simulated PGA values with that expected from an empirical function of Garcia et al. (2001) for Mexican inslab earthquakes in Figure 11. The attenuation character and PGA distribution from the 3D simulation for the 1999 Oaxaca earthquake agrees well with the observations, but the simulated PGA is about half of the observed values. This is because the higher-frequency waves, which are more important from the deep inslab earthquakes (e.g., Singh et al. 2000a), are not included in the present 3D simulation.

In Figure 9 we display the simulated record sections of horizontal component seismograms along the station profile of bb' in Figure 7. The $S m S$ reflections from this source have larger amplitudes on the transverse component, which also agrees well with the observations.

\section{Discussion}

It has long been recognized that the Valley of Mexico is vulnerable to shallow coastal earthquakes that occur on the interface of the subducting Cocos plate, even though the valley is locating over $300 \mathrm{~km}$ from the coast. The damage from interplate earthquakes may, in part, be due to the dominance of the $L g$ wave propagating in the crustal wave guide. The subhorizontal geometry of the subducted Cocos plate acts as perfect reflector for $S$ waves from interplate earthquakes. This can greatly enhance the $L g$ amplitude in the frequency range between 0.2 and $4 \mathrm{~Hz}$. In volcanic areas, the near-surface structure of low velocity also increases the amplitude and the duration of the $L g$ wave. Therefore the crustal structure of Mexican mainland acts a good propagator of $S$-wave energy in the frequency band of about 0.2 $4 \mathrm{~Hz}$. This frequency band is closely related to the resonant frequency of the clay layers in the lake-bed zone of Mexico City (0.3 to $0.7 \mathrm{~Hz}$ ) (Singh et al., 1988), so the $L g$ wave should acquire an additional amplification there (Campillo et al., 1988; Furumura and Kennett, 1998).

However, when the event occurs inside the plate, the $S$ wave radiated from the deeper source and its $\mathrm{SmS}$ multiples in the crust impinges upon the surface with almost vertical 
(a)
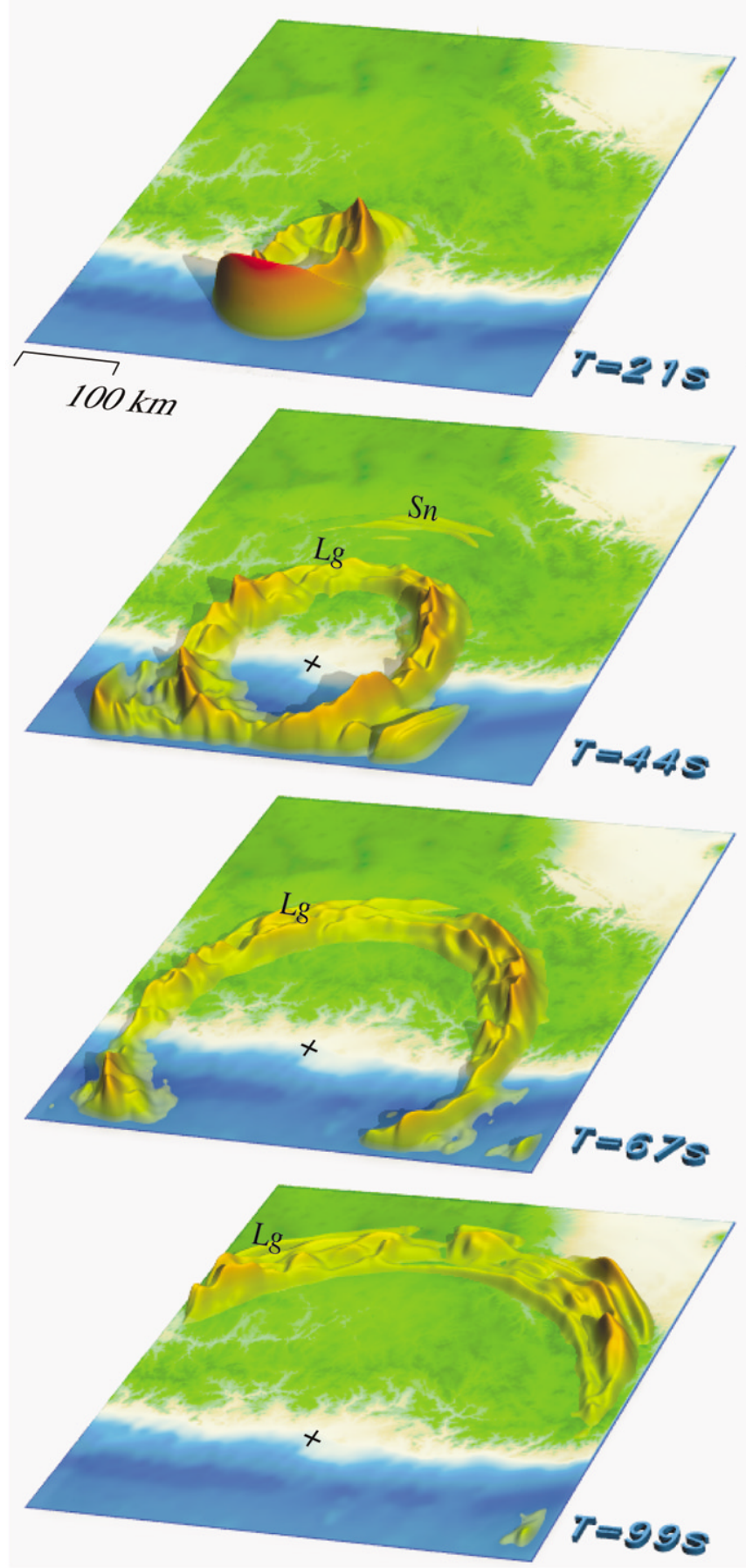

(b)
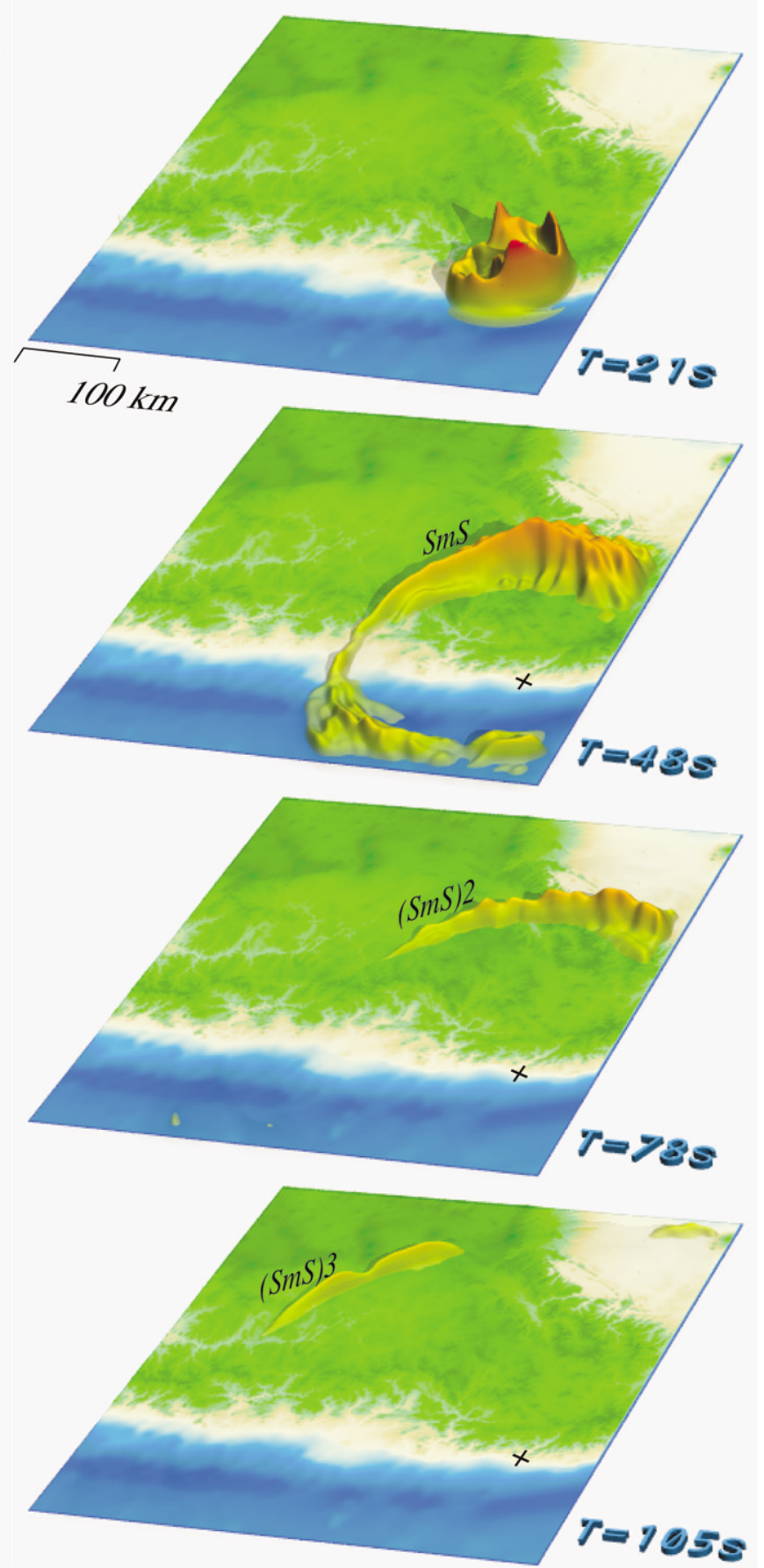

Figure 8. Snapshots of horizontal ground velocity from 3D simulation of seismicwave propagation from (a) the 1995 Guerrero earthquake and (b) the 1999 Oaxaca earthquake. The epicenters are marked by crosses. Time from the origin is shown in the bottom right corner. 


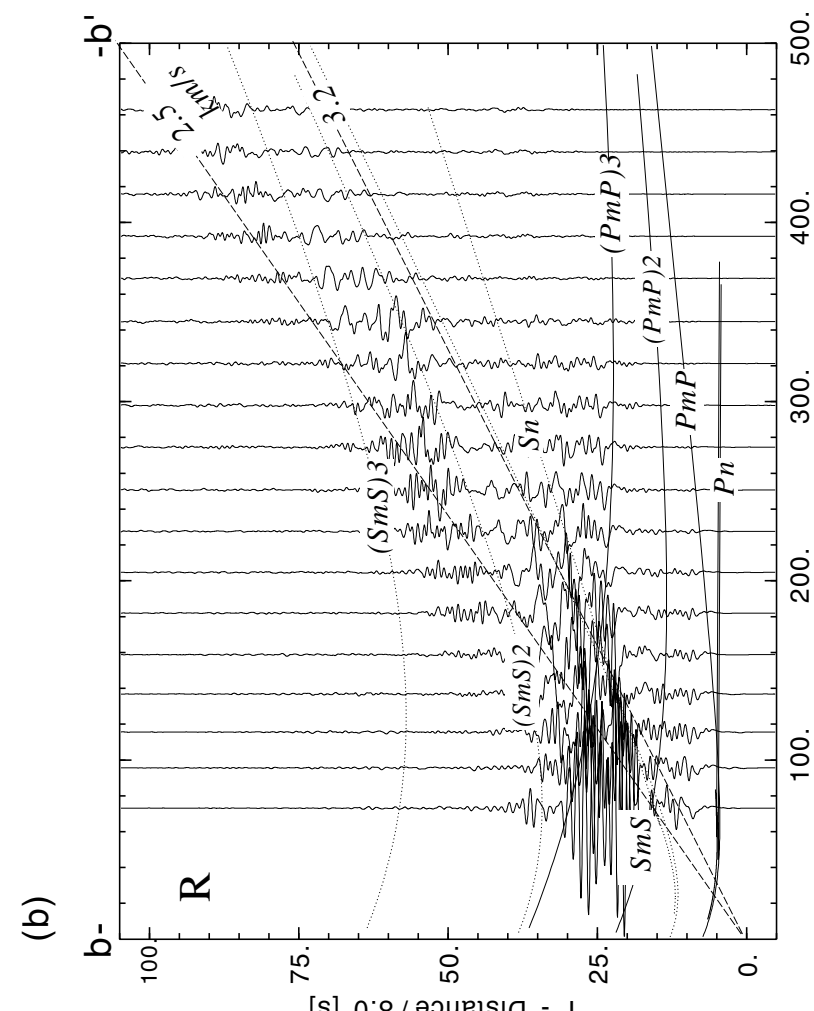

[s] 0.8 / әoue!s! - $\perp$

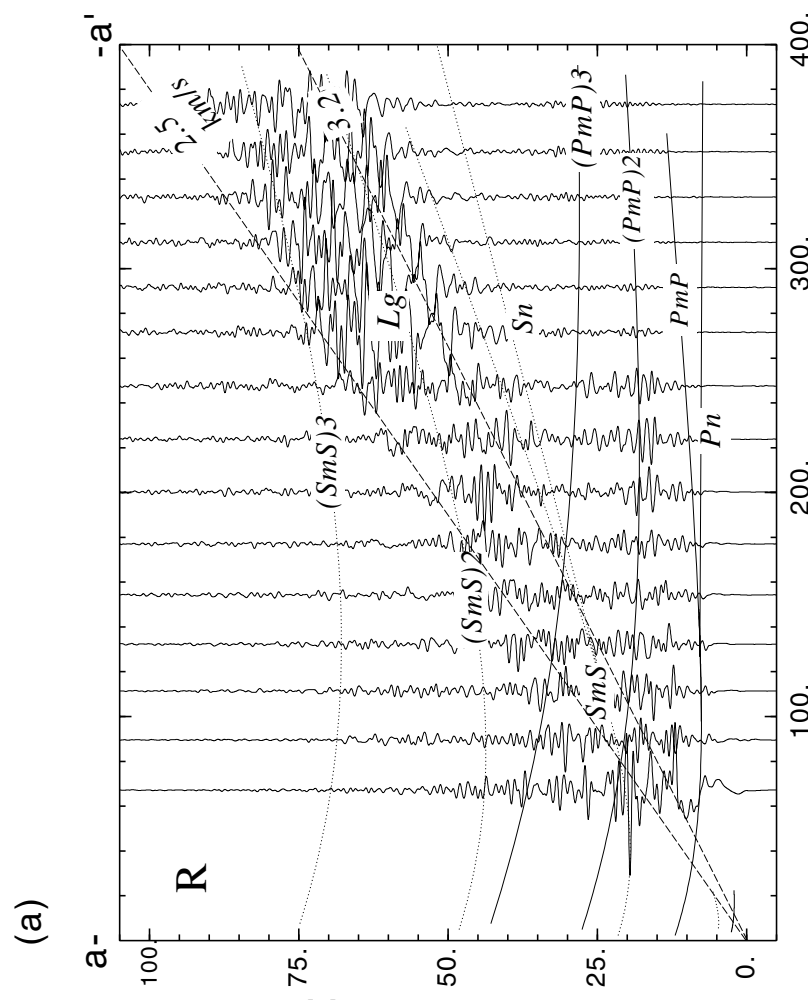

[s] 0.8 / əouels! - $\perp$

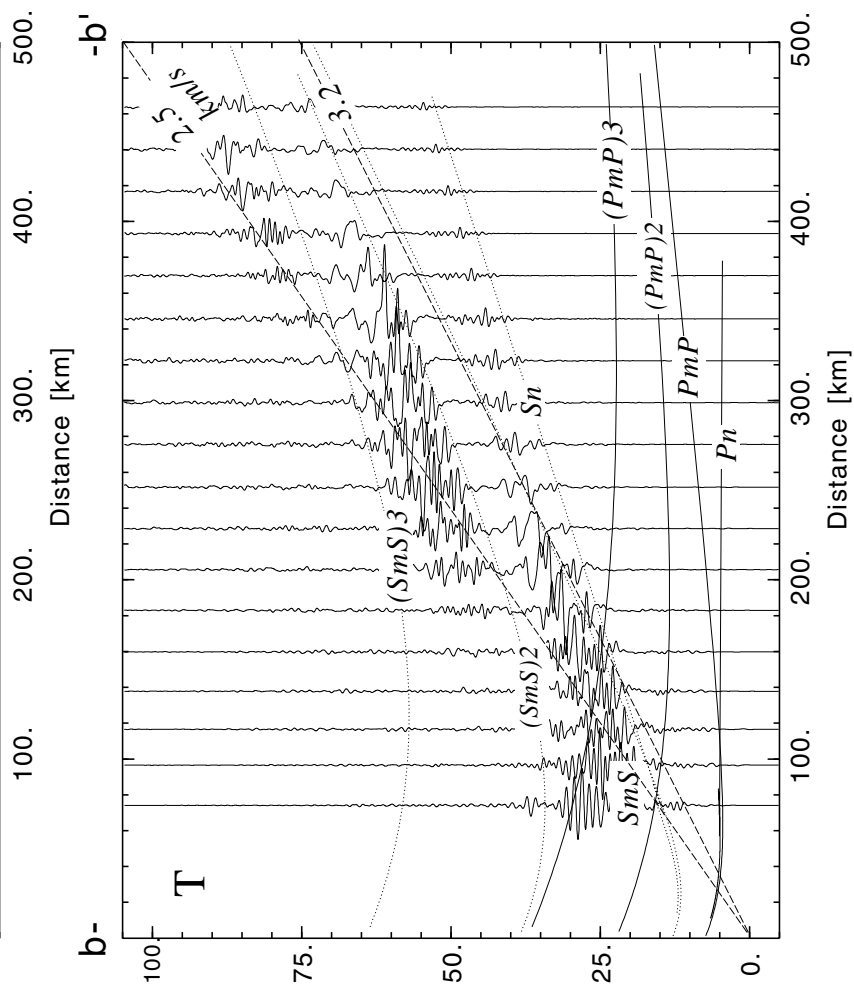

[s] 0.8 / әоие]s! - $\perp$

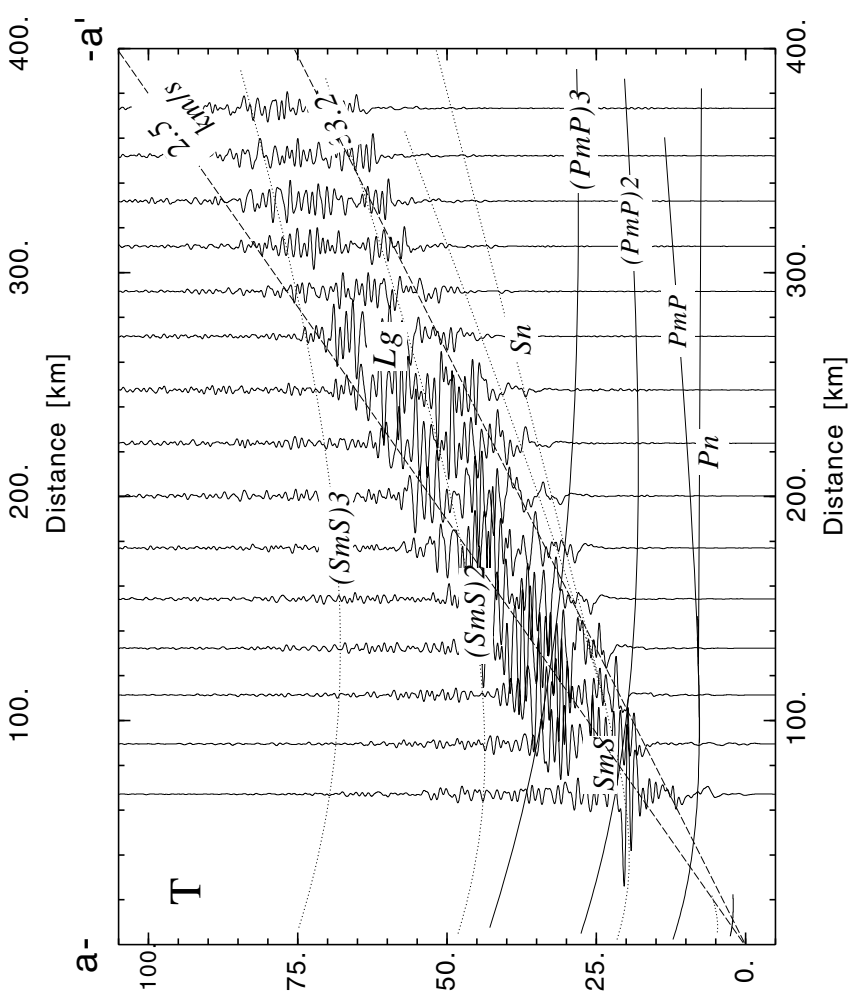

[s] 0.8 / əoueıs! - $\perp$ 
(a)
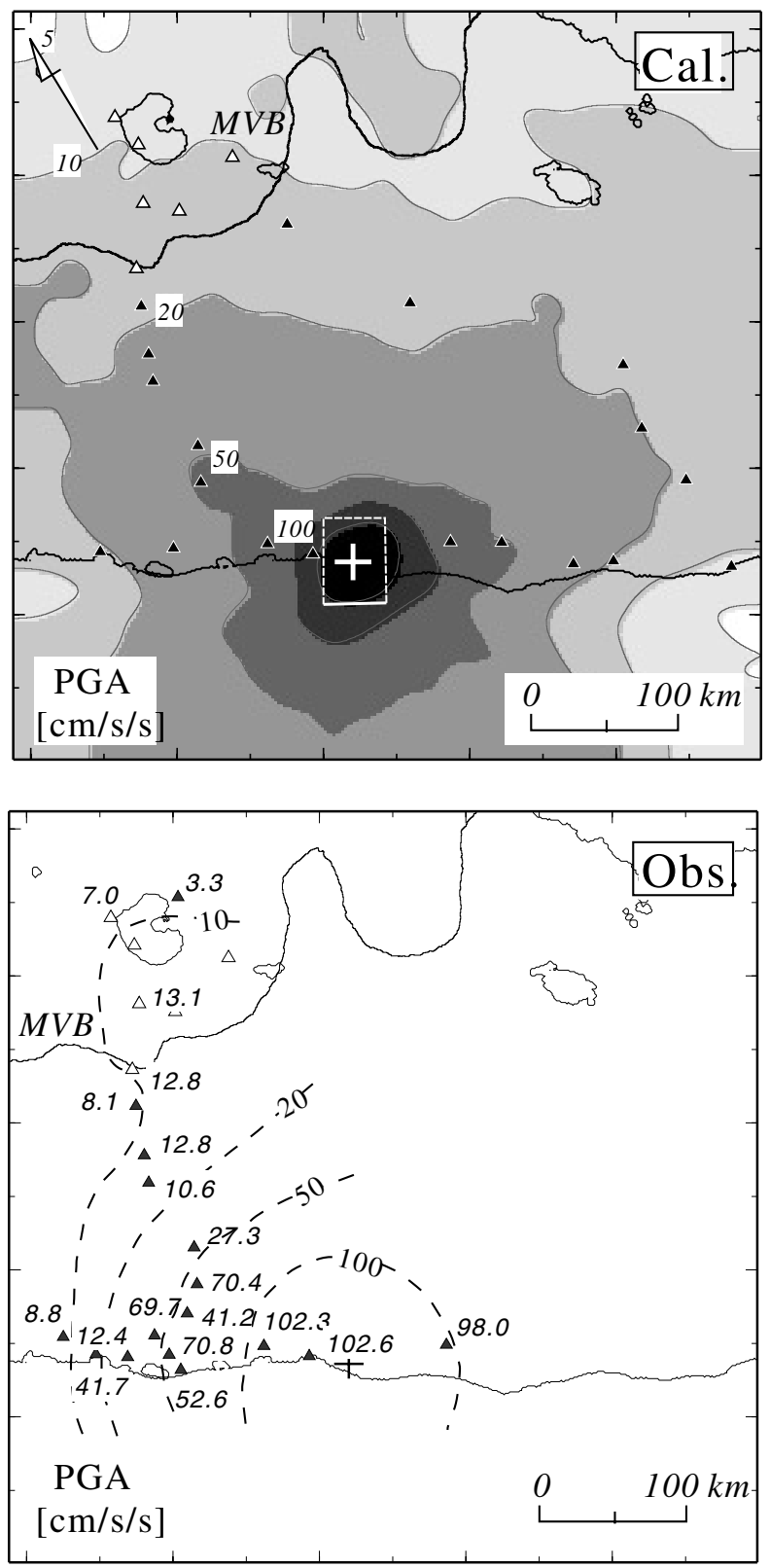

(b)
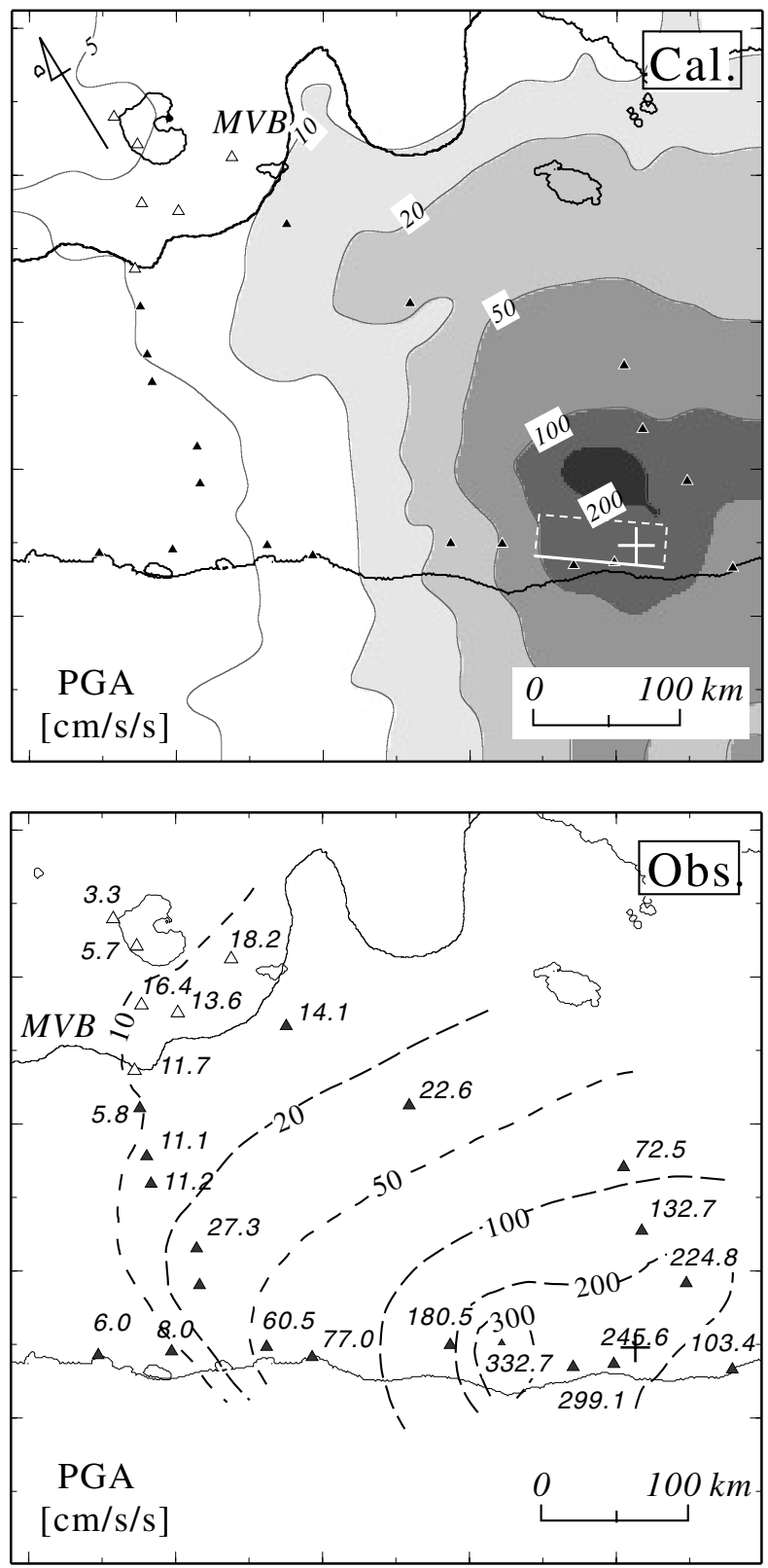

Figure 10. Peak horizontal ground acceleration. (a) The 1995 Guerrero earthquake $\left(M_{\mathrm{w}} 7.3\right)(\mathrm{b})$ the 1999 Oaxaca earthquake $\left(M_{\mathrm{w}} 7.5\right)$. (Top) 3D simulation; (bottom) observations.

incidence angle. This is a major loss of $S$-wave energy by conversion to a $P$ wave at the free surface. The amplification due to the shallow structure of the MVB is also insignificant for near-vertical incidence of the $S$ wave. Since the waveform from the inslab earthquake is characterized by the $S n$ wave and some isolated weak $S m S$ multiples, the duration of ground motion is much shorter than during interplate events with prolonged $L g$-wave trains. The result is that the $S$ wave from inslab earthquakes decays simply with increasing distances for all frequencies. This suggests that the dam- age area from inslab earthquakes should be smaller than that for interplate earthquakes, unless the stress drops during former events are much higher than for the latter ones. Recent studies on comparing seismic intensities during interplate and inslab earthquakes in Mexico suggest that the ground motions and hence the stress drop involved in the former type of events is higher than in later one (Singh et al., 2000a; Garcia et al., 2001; Iglesias et al., 2001).

Numerical 3D simulation of seismic-wave propagation using a realistic 3D model for the structure of Mexico and 
(a)

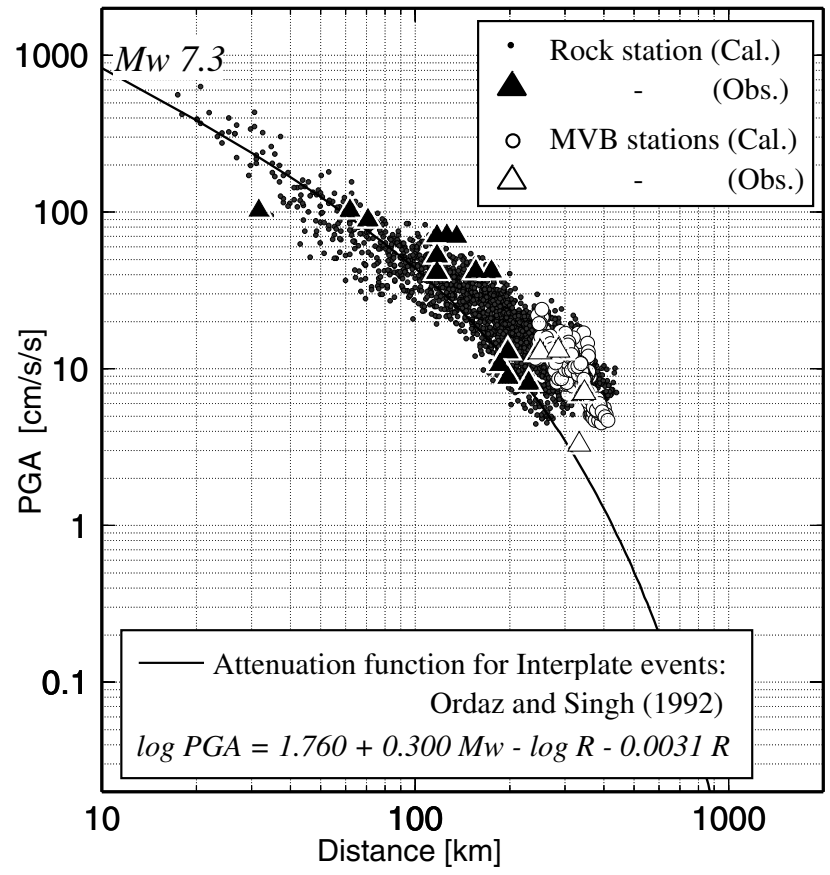

(b)

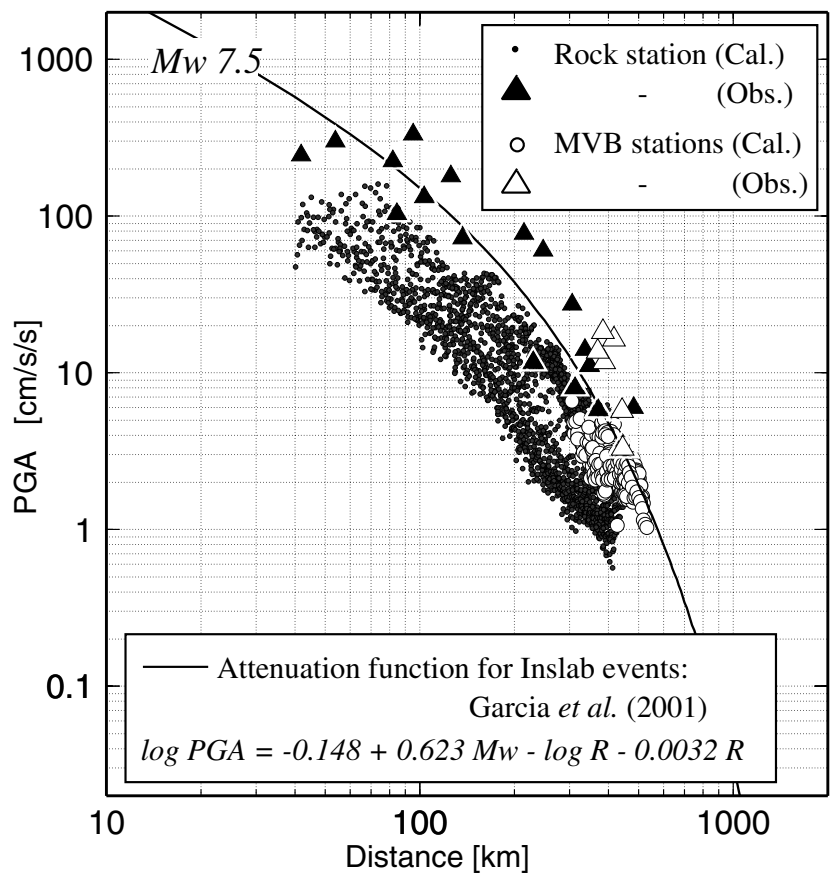

Figure 11. Comparison of observed and calculated peak horizontal ground acceleration (PGA) as a function of focal distance. (a) The 1995 Guerrero earthquake; (b) the 1999 Oaxaca earthquake. The PGA values inside the MVB are shown in white, and those outside the MVB are in black. Also shown are expected PGA value, based on regression analysis, for a shallow interplate $M_{\mathrm{w}} 7.3$ earthquake and a $M_{\mathrm{w}} 7.5$ inslab earthquake.

adequate source models provides a reasonable representation of the observed ground motion from Mexican subduction zone earthquakes for both a shallow interplate event and a deep inslab event. The model can potentially be used to investigate the pattern of ground motion expected for future events, such as at current seismic gaps, although even using current powerful computers it may still be difficult to provide an adequate resolution of the high-frequency wave field from inslab earthquakes because of the limited knowledge of heterogeneous crust and upper-mantle structure and the source-slip models during the earthquakes.

One of the important issues of strong-motion seismology is the evaluation of the damage potential in urban centers and its reduction during future scenario earthquakes. The results of this study suggest that a close link between source studies, strong-motion observations, detailed knowledge of crustal structure, and numerical simulation technology is indispensable to make substantial advances in this direction.

\section{Acknowledgments}

The collaboration of the authors has been supported by a grant-in-aid from the Japan Society for the Promotion of Science for foreign studies. The research was also partly supported by the DGAPA, UNAM projects IN109598 and IN111601. We are grateful to T. Mikumo for fruitful discussions and for his constructive remarks. The computation was conducted at the Earthquake Information Center, University of Tokyo, and at the In- stitute of Physics and Chemical Research, Japan (RIKEN). Constructive comments from the critical reading of the manuscript by Dr. R. B. Herrmann and an anonymous reviewer have been very helpful for the revision of the article.

\section{References}

Anderson, J. G., P. Bodin, J. N. Brune, J. Prince, S. K. Singh, R. Quaas, and M. Onate (1986). Strong ground motion from the Michoacan, Mexico, earthquake, Science 233, 1043-1049.

Anderson, J. G., R. Ruaas, S. K. Singh, J. M. Espionsa, A. Jiminez, J. Lermo, J. Cuenca, F. J. Sánchez-Sesma, R. Meli, M. Ordaz, S. Alcocer, B. Lopez, L. Alcantara, E. Mena, and C. Javier (1995). The Copla, Guerrero, Mexico earthquake of September 14, $1995\left(M_{\mathrm{w}}=\right.$ 7.4): a preliminary report, Seism. Res. Lett. 66, 11-39.

Barrera, T. (1931). El temblor del 14 de enero de 1931, Report, Instituto de Geologia UNAM, Mexico City, México.

Campillo, M. (1990). Propagation and attenuation characteristics of the crustal phase Lg, Pure Appl. Geophys. 132, 1-9.

Campillo, M., P.-Y. Bard, F. Nicollin, and F. Sánchez-Sesma (1988). The Mexico earthquake of September 19, 1985 the incident wavefield in Mexico City during the great Michoacán earthquake and its interpretation with the deep basin, Earthquake Spectra 4, 591-608.

Campillo, M., J. C. Gariel, K. Aki and F. J. Sánchez-Sesma (1989). Destructive strong ground motion in Mexico city: Source, path and site effects during great 1985 Michoacán Earthquake, Bull. Seism. Soc. Am. 79, 1718-1735.

Campillo, M., S. K. Singh, N. Shapiro, J. Pacheco, R. B. Herrmann (1996). Crustal structure south of the Mexican volcanic belt, based on group velocity dispersion, Geofísica Int. 35, 361-370.

Cárdenas, M., F. J. Chaez-Garía, and A. Gusev (1997). Regeonal amplifi- 
cation of ground motion in central Mexico. Results from coda-length magnitude data and preliminary modeling, J. Seismology 1, 341-355.

Cárdenas, M., F. Núñez-Cornú, J. Lermo, D. Córdoba, and A. González (1998). Seismic energy attenuation in the region between the coast of Guerrero and Mexico City: differences between paths along perpendicular to the coast, Phys. Earth. Planet. Int. 105, 47-57.

Castro, R. R., L. Munguía, C. J. Rebollar, and J. G. Acosta (1994). A comparative analysis of the quality factor $\mathrm{Q}$ for the regions of Guerrero and Oaxaca, Mexico, Geofísica Int. 33, 373-383.

Cerjan, C., D. Kosloff, R. Kosloff, and M. Reshef (1985). A nonreflecting boundary condition for discrete acoustic and elastic wave equations, Geophysics 50, 705-708.

Chávez, M., and R. Castro (1988). Attenuation of modified Mercalli intensity with distance in Mexico, Bull. Seism. Soc. Am. 78, 1875-1884.

Chávez-García, F. J. and P.-Y. Bard (1994). Site effects in Mexico City eight years after the September 1995 Michoacan earthquakes, Soil Dyn. Earthquake Eng. 13, 229-247.

Chávez-García, F. J. and J. Cuenca (1996). Site effects in Mexico City urban zone: a complementary study, Soil Dyn. Earthquake Eng. 15, 141-146.

Courboulex, F., M. A. Santoyo, J. F. Pacheco, and S. K. Singh (1997). The 14 September $1995(M=7.3)$ Copala, Mexico, earthquake: a study using teleseismic, regional, and local data, Bull. Seism. Soc. Am. 87, 999-1010.

Furumura, T., and B. L. N. Kennett (1998). On the nature of regional seismic phases III. The influence of crustal heterogeneity on the wavefield for subduction earthquakes: the 1985 Michoacan and 1995 Copala, Guerrero, Mexico earthquakes, Geophys. J. Int. 135, 1060-1084.

Furumura, T., and K. Koketsu (2000). Parallel 3-D simulation of ground motion for the 1995 Kobe earthquake: The component decomposition approach, Pure Appl. Geophys. 157, 2047-2062.

Furumura, T., and H. Takenaka (1996). 2.5-D modelling of elastic waves using the pseudospectral method, Geophys. J. Int. 124, 820-832.

Furumura, T., B. L. N. Kennett, and H. Takenaka (1998). Parallel 3-D pseudospectral simulation of seismic wave propagation, Geophysics 63, 279-288.

Furumura, T., K. Koketsu, and H. Takenaka (2000). A Hybrid PSM/FDM parallel simulation for large-scale 3D seismic (acoustic) wavefield, Butsuri-Tansa (J. SEGI) 53, 294-308, (in Japanese).

Furumura, T., K. Koketsu and K.-L. Wen (2002). Parallel PSM/FDM hybrid simulation of ground motions from the 1999 Chi-Chi, Taiwan, earthquake, Pure Appl. Geophys. 159 (in press).

Garcia, D., S. K. Singh, M. Ordaz, and M. Herraiz (2001). Determinacion de una ley de atenuacion espectral para sismos intraplaca en Mexico, Extended Abstract, II Congreso Iberoamericano de Ingenieria Sismica, Madrid, 16-17 October.

Gonalez-Ruiz, J. R. (1986). Earthquake source mechanics and tectonophysics of the middle America subduction zone in Mexico, Ph.D. Thesis, University of California, Santa Cruz.

Hernandez, B., N. Shapiro, S. K. Singh, J. F. Pacheco, F. Cotton, M. Campillo, A. Iglesias, V. Cruz, J. M. Gomez, and L. Alcantara (2001). Rupture history of September 30, 1999 intraplate earthquake of Oaxaca, Mexico $\left(\mathrm{M}_{\mathrm{w}}=7.5\right)$ from inversion of strong-motion data, Geophys. Res. Lett. 28, 363-366.

Herrmann, R. B. (1979). S-wave generation by dislocation source: a numerical study, Bull. Seism. Soc. Am. 69, 1-15.

Hermann, R. B., and A. Kijko (1983). Modeling some empirical vertical component $L g$ relations, Bull. Seism. Soc. Am. 73, 157-171.

Iglesias, A., S. K. Singh, J. F. Pacheco, and M. Ordaz (2002). A source and wave propagation study of the Copalillo, Mexico earthquake of July 21, $2000\left(\mathrm{M}_{\mathrm{w}}=5.9\right)$ : implications for seismic hazard in Mexico City from inslab earthquakes, Bull. Seism. Soc. Am. 92, 1060-1071.

Iida, M (1999) Excitation of high-frequency surface waves with long duration in the Valley of Mexico, J. Geophys. Res. 104, 7329-7345.

Kawase, H., and K. Aki (1989). A study on the response of a soft basin for incident $S, P$, and Rayleigh waves with spectral reference to the long duration observed in Mexico City, Bull. Seism. Soc. Am. 79, 13611382.

Kennett, B. L. N. (1985). On regional S. Bull. Seism. Soc. Am. 75, 10771086.

Kosloff, D., M. Reshef, and D. Loewenthal (1984). Elastic wave calculation by the Fourier method, Bull. Seism. Soc. Am. 74, 875-891.

Kostoglodov, V., W. Bandy, J. Domínguez, and M. Mena (1996). Gravity and seismicity over the Guerrero seismic gap, Mexico, Geophys. Res. Lett. 23, 3385-3388.

Mikumo, T., S. K. Singh, and M. Santoyo (1999). A possible stress interaction between large thrust and normal faulting earthquakes in the Mexican subduction zone, Bull. Seism. Soc. Am. 89, 1418-1427.

Ordaz, M., and S. K. Singh (1992). Source spectra and spectral attenuation of seismic waves from Mexican earthquakes, and evidence of amplification in the hill zone of Mexico City, Bull. Seism. Soc. Am. 82, $24-43$.

Ottemöller, L., N. M. Shapiro, S. K. Shigh, and J. F. Pacheco (2002). Lateral variation of $\mathrm{Lg}$ wave propagation in southern Mexico, J. Geophys. Res. 10, 1029.

Pacheco, J. F., and S. K. Singh (1995). Estimation of ground motion in the Valley of Mexico from normal-faulting, intermediate-depth earthquakes in the subducted Cocos plate, Earthquake Spectra 11, 233 248.

Pardo, M., and G. Suárez (1995). Shape of subducted Rivera and Cocos plates in Southern Mexico: seismic and tectonic implications, J. Geophys. Res. 100, 12,357-12,373.

Quintanar, L., J. Yamamoto, and Z. Jimenez (1999). Source mechanism of two 1994 intermediate-depth-focus earthquakes in Guerrero, Mexico, Bull. Seism. Soc. Am. 89, 1004-1018.

Reshef, M., D. Kosloff, M. Edwards, and C. Hsiung (1988). Three-dimensional elastic modeling by the Fourier method, Geophysics 53, 1184 1199.

Sánchez-Sesma, F. J., S. Chávez-Pérez, M. Suárez, M. A. Bravo, and L. E. Pérez-Rocha (1988). On the seismic response of the Valley of Mexico, Earthquake Spectra 4, 569-589.

Sánchez-Sesma, F. J., L. E. Pérez-Rocha, and E. Reinoso (1993). Ground motion in Mexico City during the April 25, 1989, Guerrero earthquake, Tectonophysics 218, 127-140.

Shapiro, N. M., M. Campillo, A. Paul, S. K. Singh, D. Jongmans, and F. J. Sánchez-Sesma (1997). Surface-wave propagation across the Mexican Volcanic Belt and the origin of the long-period seismic-wave amplification in the Valley of Mexico, Geophys. J. Int. 128, 151-166.

Singh, S. K., and M. Wyss (1976). Source parameters of the Orizaba earthquake of August 28, 1973, Geofisica Int. 16, 165-184.

Singh, S. K., V. Kostoglodov, and J. F. Pacheco (2000a). Intraslab earthquakes in the subducting oceanic plates below Mexico (abstract), Abstracts of the Intraslab Earthquakes Workshop, Victoria, B.C., 18-21 September, 59-63.

Singh, S. K., E. Mena, and R. Castro (1988). Some aspects of source characteristics of the 19 September 1985 Michoacan earthquake and ground motion in and near Mexico City from strong motion data, Bull. Seism. Soc. Am. 78, 451-477.

Singh, S. K., A. Mori, E. Mena, F. Krüger, and R. Kind (1990). Evidence for anomalous body-wave radiation between 0.3 and $0.7 \mathrm{~Hz}$ from the 1985 September 19 Michoacan, Mexico earthquake, Geophys. J. Int. 101, 37-48.

Singh, S. K., M., Ordaz, L. Alcántara, N. Shapiro, V. Kostoglodov, J. F. Pacheco, S. Alcocer, C. Gutierrez, R. Quaas, T. Mikumo, and E. Ovando (2000b). The Oaxaca earthquake of September 30, $1999\left(\mathrm{M}_{\mathrm{w}}\right.$ $=7.5$ ): a normal-faulting event in the subducted Cocos Plate, Seism. Res. Lett. 71, 67-78.

Singh, S. K., M. Ordaz, J. F. Pacheco, R. Quaas, L. Alcántara, S. Alcocer, C. Gutierrez, R. Meli, and E. Ovando (1999). A preliminary report on the Tehuacán, México earthquake of June 15, $1999\left(\mathrm{M}_{\mathrm{w}}=7.0\right)$, Seism. Res. Lett. 70, 489-504.

Singh, S. K., R. Quaas, M. Ordaz, F. Mooset, D. Almora, M. Torres, and 
R. Vásquez (1995). Is their truly a "Hard" rock site in the Valley of Mexico? Geophys. Res. Lett. 22, 481-484.

Singh, S. K., M. Reichle, and J. Havskov (1980). Magnitude and epicenter determinations of Mexican earthquakes from isoseismic maps, Geofísica Int. 19, 269-284.

Singh, S. K., G. Suárez, and T. Domínguez (1985). The Oaxaca, Mexico, earthquake of 1931: lithospheric normal faulting in the subducted Cocos plate, Nature 317, 56-58.

Valdes, C. M., and R. P. Meyer (1996). Seismic structure between the Pacific coast and Mexico City from the Petatlán earthquake $\left(\mathrm{M}_{\mathrm{s}}=\right.$ 7.6) aftershocks, Geofisica Int. 35, 377-401.

Valdes, C. M., W. D. Mooney, S. K. Singh, R. P. Meyer, C. Lomnitz, J. H. Luetgert, C. E. Helsley, B. T. R. Lewis, and M. Mena (1986). Crustal structure of Oaxaca, Mexico, from seismic refraction measurements, Bull. Seism. Soc. Am. 76, 547-563.

Yamamoto, J., Z. Jimenéz, and R. Mota (1984) El temblor de Huajuapan de Leon, Oaxaca, México del 24 de Octobre de 1980, Geofisica Int. 23, 93-110.

Earthquake Research Institute

University of Tokyo

1-1-1 Yayoi, Bunkyo-ku

113-0032, Japan

furumura@eri.u-tokyo.ac.jp

(T.F.)

Instituto de Geofísica

Universidad Nacíonal Autónoma de México

Ciudad Universitaria

Coyoacán, 04510, México D.F.

(S.K.S.)

Manuscript received 23 October 2001. 